\title{
TRPM4-dependent post-synaptic depolarization is essential for the induction of NMDA receptor-dependent LTP in CA1 hippocampal neurons
}

\author{
Aurélie Menigoz $^{1,3}$ - Tariq Ahmed ${ }^{2,3} \cdot$ Victor Sabanov $^{2,3} \cdot$ Koenraad Philippaert $^{1,3}$. \\ Silvia Pinto ${ }^{1,3}$ • Sara Kerselaers ${ }^{1,3}$ • Andrei Segal ${ }^{1,3}$ • Marc Freichel $^{4}$ • Thomas Voets ${ }^{1,3}$. \\ Bernd Nilius $^{1,3} \cdot$ Rudi Vennekens ${ }^{1,3} \cdot$ Detlef Balschun ${ }^{2,3}$
}

Received: 12 November 2015 / Accepted: 18 November 2015 / Published online: 3 December 2015

(C) The Author(s) 2015. This article is published with open access at Springerlink.com

\begin{abstract}
TRPM4 is a calcium-activated but calciumimpermeable non-selective cation (CAN) channel. Previous studies have shown that TRPM4 is an important regulator of $\mathrm{Ca}^{2+}$-dependent changes in membrane potential in excitable and non-excitable cell types. However, its physiological significance in neurons of the central nervous system remained unclear. Here, we report that TRPM4 proteins form a CAN channel in CA1 neurons of the hippocampus and we show that TRPM4 is an essential co-activator of $N$-methyl-D-aspartate (NMDA) receptors (NMDAR) during the induction of longterm potentiation (LTP). Disrupting the Trpm 4 gene in mice specifically eliminates NMDAR-dependent LTP, while basal synaptic transmission, short-term plasticity, and NMDARdependent long-term depression are unchanged. The induction of LTP in Trpm $4^{-1-}$ neurons was rescued by facilitating NMDA receptor activation or post-synaptic membrane depolarization. Accordingly, we obtained normal LTP in Trpm $4^{-1}$ neurons in a pairing protocol, where post-synaptic
\end{abstract}

Aurélie Menigoz, Tariq Ahmed, and Victor Sabanov share first authorship.

Rudi Vennekens and Detlef Balschun share last authorship.

Rudi Vennekens

rudi.vennekens@med.kuleuven.be

1 Laboratory of Ion Channel Research, Department of Cellular and Molecular Medicine, University of Leuven, Herestraat 49, bus 802, 3000 Leuven, Belgium

2 Laboratory of Biological Psychology, University of Leuven, Tiensestraat 102, 3000 Leuven, Belgium

3 TRP Research Platform Leuven (TRPLe), University of Leuven, 3000 Leuven, Belgium

4 Pharmakologisches Institut, Universität Heidelberg, Im Neuenheimer Feld 366, 69120 Heidelberg, Germany depolarization was applied in parallel to pre-synaptic stimulation. Taken together, our data are consistent with a novel model of LTP induction in CA1 hippocampal neurons, in which TRPM4 is an essential player in a feed-forward loop that generates the post-synaptic membrane depolarization which is necessary to fully activate NMDA receptors during the induction of LTP but which is dispensable for the induction of longterm depression (LTD). These results have important implications for the understanding of the induction process of LTP and the development of nootropic medication.

Keywords Transient receptor potential ion channels $\cdot$ Long term potentiation - Synaptic transmission - Synaptic plasticity TRPM4

\section{Introduction}

The cellular and molecular mechanisms underlying cognitive brain functions and their deterioration by neurodegenerative and neuropsychiatric disorders are a central theme in contemporary neuroscience. It is widely accepted that during learning, complex sensorial inputs are encoded as changes in the synaptic efficacy of activated neuronal networks. At the level of individual synaptic connections, this is reflected in either long-lasting increases in synaptic efficacy (long-term potentiation (LTP)), long-lasting decreases (LTD), or a reset of previously increased or decreased efficacy to a new level (depotentiation and dedepression, respectively). Of these different forms of synaptic plasticity, LTP was the first that was discovered in the hippocampal formation [2]. $\mathrm{Ca}^{2+}$ influx through the $N$-methyl-D-aspartate (NMDA) subtype of glutamate receptors, upon strong post-synaptic depolarization and removal of the $\mathrm{Mg}^{2+}$ block from NMDA receptors 
(NMDAR), is widely accepted as the central trigger of LTP induction $[1,24]$. Once the increase in intracellular $\mathrm{Ca}^{2+} \mathrm{ex}-$ ceeds a critical threshold value, biochemical processes necessary for LTP induction and expression are activated by molecular crosstalk within the multiprotein complex of the post-synaptic density (PSD) [20]. Many proteins and molecules have been reported to be important for LTP expression, but only a few have been identified as critical for LTP induction, such as calcium/calmodulin-dependent protein kinase II (CaMKII), cyclic adenosine monophosphate-dependent protein kinase (PKA), protein kinase $\mathrm{C}$ (PKC), and the extracellular signal-regulated kinase (Erk)/mitogen-activated protein kinase (MAPK) pathway [7]. In contrast to the increasing complexity of LTP mechanisms downstream of NMDAR activation, the upstream mechanisms of post-synaptic depolarization in response to pre-synaptic glutamate release are fairly established during the last decades, pointing to a dominant contribution of AMPA receptors modulated by dendritic voltage-gated $\mathrm{Ca}^{2+}, \mathrm{Na}^{+}, \mathrm{K}^{+}$, and $\mathrm{I}_{\mathrm{h}}$ channels [3].

Here, we report a novel critical mediator of LTP induction upstream of NMDA receptor activation. We present different lines of experimental evidence, which support that activation of the transient receptor potential (TRP) channel M4 (TRPM4), a calcium-activated, but calcium-impermeable non-selective cation channel, is mandatory for NMDAR activation and the induction of LTP. The TRPM4 belongs to the melastatin subfamily of the TRP membrane proteins. TRP channels are well described for their role in sensory signaling and can be gated by a large variety of stimuli, from chemical to mechanical and to changes in temperature [11]. Among this family of 28 ion channels, TRPM4 and its closest structural relative TRPM5 exhibit some unique properties (for a review, see [23]). TRPM4 expression has been reported in a large range of tissues including several parts of the cardiovascular system and immune cells such as T cells and mast cells [17, 29]. Several studies have also detected TRPM4 messenger RNA (mRNA) and protein in the brain of rodents and humans $[31,40]$. Recently, excessive TRPM4 activity has been associated with neuronal cell death in experimental autoimmune encephalomyelitis, a mouse model of multiple sclerosis [31].

\section{Material and methods}

\section{Animals}

Trpm $4^{-/}$transgenic mice were previously described [37]. Female $\operatorname{Trpm}^{-/}$and wild-type (WT) littermates, aged between 8 and 12 weeks, were used for all experiments. All animal experiments were in accordance with the European Community Council Directive (86/609/EC) and approved by the local ethics committee.

\section{In situ staining}

Control and Trpm $4^{--}$mouse brains were dissected out in phosphate-buffered saline (PBS) and fixed in $4 \%$ paraformaldehyde (PFA) for $2 \mathrm{~h}$ at RT and cryopreserved in $25 \%$ sucrose overnight at $4{ }^{\circ} \mathrm{C}$ before embedding in optimal cutting temperature (OCT) compound (Tissue-Tek, Sigma-Aldrich). Sections of $12 \mu \mathrm{m}$ were cut on a cryostat, collected on ProbeOn Plus microscope slides (Fisher Scientific), and stored at $-80^{\circ} \mathrm{C}$ until used.

The mouse TRPM4 (NM_175130.4) PCR product was amplified from a plasmid using the following oligonucleotides: sense 5'- CCAGGACCGCAGTCTACCGAGTA 3' and antisense 5'- GGCAAGTTAGCCCTGCGACACCT $3^{\prime}$ and cloned into a pGEM easy vector (Promega). Sense and antisense digoxigenin (DIG) probes were generated in a $5-\mu l$ reaction containing 100-200 ng of linearized plasmid, using DIG RNA labeling mix (Roche Diagnostics) SP6 and T7 RNA polymerase (Invitrogen) following the manufacturer's instructions. DIG-labeled riboprobes were ethanolprecipitated with $\mathrm{LiCl}$, washed with $70 \%$ ethanol, and resuspended in sterile DNase/RNase-free water. In situ hybridizations were performed essentially as described in [32]. Briefly, after hybridization overnight at $65{ }^{\circ} \mathrm{C}$ with a riboprobe, the slices were washed twice in $1 \times \mathrm{SSC}, 50 \%$ formamide, and $0.1 \%$ Tween- 20 at $65{ }^{\circ} \mathrm{C}$ for $30 \mathrm{~min}$ and blocked in the presence of $2 \%$ blocking reagent and $20 \%$ inactivated sheep serum. The slides were then incubated with anti-DIG-alkalinephosphatase (AP)-conjugated antibody (Roche Diagnostics), washed, and revealed with NBT/BCIP staining.

\section{Protein extraction and immunoblotting}

Proteins from freshly isolated hippocampus, of wild-type and Trpm $^{-/}$mice, were lysed in $1 \mathrm{ml}$ of lysis buffer $(100 \mathrm{mM}$ Tris $\mathrm{pH} 8,1 \mathrm{mM} \mathrm{MgCl} 2,100 \mu \mathrm{M}$ phenylmethylsulfonyl fluoride (PMSF), and a protease inhibitors' cocktail $(10 \mu \mathrm{g} / \mathrm{ml}$ leupeptin and antipain, $2 \mu \mathrm{g} / \mathrm{ml}$ chymostatin and pepstatin)) using the Polytron homogenizer (Kinematica AG, Switzerland). After removal of nuclei, mitochondria, and any remaining large cellular fragments, pre-cleared supernatants were ultracentrifuged at $500,000 \mathrm{~g}$ for $30 \mathrm{~min}$ at $4{ }^{\circ} \mathrm{C}$. Pellets containing total membrane fractions were solubilized, and $60 \mu \mathrm{g}$ was subjected to SDS-polyacrylamide gel electrophoresis (SDS-PAGE) and subsequently transferred to a polyvinylidene fluoride (PVDF) membrane (Bio-Rad, USA). Respective proteins were detected with purified polyclonal rabbit anti-TRPM4 (1:1000 dilution), polyclonal rabbit anti CaMKII (1:1000, Cell Signaling), polyclonal rabbit phospho- $\alpha$ CaMKII (thr286) (1:1000, Cell Signaling), and monoclonal mouse anti- $\mathrm{Na}^{+} / \mathrm{K}^{+}$ATPase (1: 5000 dilution) (Abcam, UK) antibodies. Immunoreactive complexes were 
visualized by chemiluminescence, using anti-rabbit IgG (Sigma, USA) or anti-mouse IgG (GE Healthcare) antibodies conjugated to horseradish peroxidase (1: 40,000 and 1: $5000 \mathrm{di}-$ lutions, respectively).

\section{Hematoxylin and eosin staining}

Brains of control and Trpm $4^{-1}$ were dissected out in PBS and immersed in $4 \%$ PFA for $2 \mathrm{~h}$ at RT. Samples were then placed in $25 \%$ sucrose overnight at $4{ }^{\circ} \mathrm{C}$ for cryoprotection, embedded in OCT, and frozen. Coronal $12-\mu \mathrm{m}$ sections containing the hippocampal area were prepared using a cryostat. Hippocampus sections were stained with hematoxylin and eosin in accordance with the standard procedure.

\section{Golgi staining and morphological analysis}

Golgi staining was performed according to the manufacturer's instruction (Rapid Golgi staining kit, FD Neurotechnologies, Inc., Ellicott City, MD, USA). Coronal sections (120 $\mu \mathrm{m})$ containing identical regions of the hippocampus were selected from WT and Trpm $4^{--}$mice for analysis. Neurons chosen for analysis had to possess the following characteristics: (i) cell bodies had to be located in the middle third of the slice to avoid analysis of neurons extending into other sections; (ii) dark impregnation through all the dendrites, without breaks; and (iii) the neurons had to be isolated from the neighboring impregnated cells to avoid interferences in analysis. The branching density of the apical dendritic trees of CA1 pyramidal neurons was evaluated using the Sholl method [19], where spine density and length of dendrites arising from the soma are determined in the first- $(50 \mu \mathrm{m})$, second- $(50$ $100 \mu \mathrm{m})$, and third-order segments $(100-150 \mu \mathrm{m})$ from the center of the soma. The number of intersections between the dendrites and the concentric circles was counted and plotted as a function of the distance from the soma. Tracing and counting were performed with a $\times 100$ oil immersion objective (Zeiss). Curvilinear lengths were measured with Image $\mathrm{J}$ software. The spine density was measured on secondary branches situated in the proximal apical area (30-120 $\mu \mathrm{m}$ from the soma). On average, 4-8 neurons were included per animal, and five animals were analyzed per genotype. A MAP2 immunostaining on a separate set of slices was used to assess the neuronal density. Briefly, cryosections containing dorsal region of the hippocampus were probed with anti-MAP2 antibody (\#4542; Cell Signaling) for $1 \mathrm{~h}$ at room temperature and revealed with anti-rabbit IgG antibody (Alexa fluor 488 conjugate; \#4412; Cell Signaling). Images were acquired and analyzed using an Apotome (Zeiss). The number of pyramidal-shaped MAP2positive cells in the CA1 area was determined per $\mathrm{mm}^{2}$. Three fields per slices, four slices per animal, and five animals per genotype were analyzed. All these analyses were performed blind to the genotype of subjects.

\section{Electrophysiology}

\section{Multi-electrode array recording}

Mice were sacrificed by cervical dislocation, decapitated, and brains transferred to ice-cold oxygenated $\left(95 \% \mathrm{O}_{2}, 5 \% \mathrm{CO}_{2}\right)$ artificial cerebrospinal fluid (aCSF; in $\mathrm{mM}$ ): $\mathrm{NaCl}, 124 ; \mathrm{KCl}$, 3; $\mathrm{NaHCO}_{3}, 26 ; \mathrm{NaH}_{2} \mathrm{PO}_{4}, 1.25 ; \mathrm{MgSO}_{4}, 1$; glucose, 10 ; $\mathrm{CaCl}_{2}$. Hippocampi were horizontally sliced $(250 \mu \mathrm{m}$ thick $)$ in a vibratome filled with ice-cold oxygenated aCFS. Hippocampal slices were allowed to recover in an interface chamber filled with oxygenated solution at room temperature for at least $2 \mathrm{~h}$. Then, they were placed in a multi-electrode array (MEA) recording chamber and perfused continuously at a rate of $2 \mathrm{ml} / \mathrm{min}$ with aCSF at $32^{\circ} \mathrm{C}$.

Extracellular stimulations and recordings were performed with a MEA set-up (Multi Channels Systems, Reutlingen, Germany) consisting of a MEA1060-BC preamplifier, a filter amplifier (gain $1100 \times$ ), and a twochannel stimulus generator (STG2002). MEA biochips with $8 \times 8$ titanium nitrite electrodes $(30-\mu \mathrm{m}$ diameter and $200-\mu \mathrm{m}$ spacing) were used. The bath was grounded with an internal reference electrode. Slice position and contact with the electrodes were secured with a nylon mesh (ALA Scientific Instruments, USA). Stimulation electrodes were positioned at the Schaffer collateral pathway, and evoked field excitatory post-synaptic potentials (fEPSPs) were monitored at proximal stratum radiatum. Data acquisition was performed and controlled by MC_Rack 3.2.1.0 and MC_Stimulus II software (Multichannel Systems, Reutlingen, Germany).

Input/output curves were obtained 20 min after placing the slice on the biochip. Test stimuli were delivered as biphasic pulses (100- $\mu$ s pulse width) at increasing voltages. For each stimulation, data from three consecutive fEPSPs were collected. Baseline stimulation strength for the rest of the experiments was set to produce $40 \%$ of maximal response.

LTP was induced after $40 \mathrm{~min}$ of stable baseline by one of the following protocols: 1 or multiple trains of theta-burst stimulation (TBS, 5 bursts of 4 pulses at $100 \mathrm{~Hz}$ repeated at 200-ms interval) or high-frequency stimulation (HFS, $1 \mathrm{~s}$ at $100 \mathrm{~Hz}$ ). LTP was expressed as the percent change in the average slope of the fEPSP taken from 40 to $60 \mathrm{~min}$ after LTP induction in relation to the average fEPSP slope during the 10-min baseline recording that preceded the conditioning protocol.

For electrically evoked LTD, low-frequency stimulation (LFS) consisting of 1500 pulses at $1 \mathrm{~Hz}(0.2-\mathrm{ms}$ pulse width) was applied [10]. Immediately after the conditioning stimulus, evoked responses were monitored every $5 \mathrm{~min}$ up to $4 \mathrm{~h}$. Chemically induced long-term depression [33] was induced by bath application of the selective mGluR group I agonist (S)-3,5-dihydroxyphenylglycine (DHPG; $30 \mu \mathrm{M}$ for $15 \mathrm{~min}$ ). 
In all experiments, the recording of slices from mutant mice was interleaved by experiments with wild-type controls.

Most recording also included a paired-pulse protocol with following interpulse intervals: 20-50-100-200 ms. Data from three consecutive fEPSPs were collected for each stimulation interval. Paired-pulse facilitation (PPF) was calculated as the ratio of the slope from the second to the first response for each paired stimulation event.

\section{Whole-cell patch-clamp recording}

Following decapitation, brains were isolated as described above and transverse (400 $\mu \mathrm{m}$ thick) hippocampal slices were prepared with a vibratome (MIKROM HM 650V Microm Instruments GmbH, Wallsdorf, Germany) and stored at room temperature in a holding bath containing oxygenated aCSF. After a recovery period of at least $1 \mathrm{~h}$, an individual slice was transferred to the recording chamber where it was continuously superfused with oxygenated aCSF at a rate of $2.5 \mathrm{ml} / \mathrm{min}$. Wholecell recordings from CA1 pyramidal neurons were performed using a patch-clamp amplifier (MultiClamp 700B, Axon Instruments, Molecular Devices, Inc., Sunnyvale, CA, USA). Neuronal patching was performed under visual control by an infrared differential interference contrast optics system (Axioskop2 FC Plus, Zeiss Instruments, Jena, Germany).

To measure TRPM4 currents in CA1 pyramidal neurons from acute hippocampal slices, we performed voltage-clamp recordings during depolarizing ramps from -115 to $+35 \mathrm{mV}$ in $200 \mathrm{~ms}\left(V_{\mathrm{h}}=-85 \mathrm{mV}, T=32^{\circ} \mathrm{C}\right.$, $)$ in the presence of high free $\mathrm{Ca}^{2+}(10 \mu \mathrm{M})$ in the pipette solution $\left(132 \mathrm{CsMeSO}_{4}, 4 \mathrm{NaCl}\right.$, 0.2 Na-GTP, 2 Mg-ATP, $2 \mathrm{MgCl}_{2}, 0.5 \mathrm{NaEGTA}, 0.69 \mathrm{CaCl}_{2}$ $\left(10 \mu \mathrm{M}\right.$ free $\left.\mathrm{Ca}^{2+}\right)$, $10 \mathrm{~K}$-HEPES, 5 QX-314; pH 7.27, $285 \mathrm{mOsm})$. As a control, we patched CA1 pyramidal cells from the same slices with $\mathrm{Ca}^{2+}$-free pipette solution (132 $\mathrm{CsMeSO}_{4}, 4 \mathrm{NaCl}, 0.2 \mathrm{Na}-\mathrm{GTP}, 2 \mathrm{Mg}-\mathrm{ATP}, 2 \mathrm{MgCl}_{2}, 2.5$ NaEGTA, 10 K-HEPES, 5 QX-314; pH 7.26, 287 mOsm). Special precautions were undertaken for the sufficient dialysis of the patched cells. For this purpose, big-tip-diameter pipettes (1.5-3 M $\Omega$ ) were used so that stable ( $80 \%)$ Rs was always kept below $15 \mathrm{M} \Omega$ and recordings were started at least $15 \mathrm{~min}$ after establishing the w/c configuration. In order to eliminate tentative "contaminating" current components, the bath medium was supplemented with the following drugs: $2 \mu \mathrm{M}$ TTX (voltage-gated $\mathrm{Na}^{+}$channel blocker), $40 \mu \mathrm{M}$ CNQX and $50 \mu \mathrm{M}$ DL-AP5 (to block glutamatergic AMPA and NMDA receptors, respectively), $100 \mu \mathrm{M}$ picrotoxin $\left(\mathrm{GABA}_{\mathrm{A}}\right.$ blocker), $50 \mu \mathrm{M}$ nifedipine (L-type calcium channel blocker), $20 \mu \mathrm{M}$ flunarizine (T-type $\mathrm{Ca}^{2+}$ channel blocker), and $1 \mu \mathrm{M}$ $\omega$-Conotoxin MVIIC (blocks N, P, and Q-type $\mathrm{Ca}^{2+}$ channels). Slices were perfused with this medium at least $20 \mathrm{~min}$ prior to recording.
To establish the basic membrane properties and intrinsic excitability of the CA1 pyramidal cells, we measured voltage responses to $500-\mathrm{ms}$ duration $-100 \mathrm{pA}$ (hyperpolarizing) and $+200 \mathrm{pA}$ (depolarizing) current injections applied to the individual neuron at resting potential. Input resistance was calculated using Ohm's law applied to the peak voltage amplitude in response to a $500-\mathrm{ms}$ injection of $100-\mathrm{pA}$ hyperpolarizing current. Membrane time constants were measured from the same voltage responses through single exponential fitting of the recording trace from the onset of voltage deflection to the peak of the membrane charging curve. Voltage sag (a hallmark of hyperpolarization-activated currents) was quantified as the ratio of the steady-state voltage amplitude over the peak amplitude in response to hyperpolarizing step. Action potential parameters were measured from the first spike in response to depolarizing pulse. Spike after-depolarization (ADP) was measured following a single action potential elicited by a $2-\mathrm{ms}$ depolarizing current pulse of $+2 \mathrm{nA}$. Current-clamp recordings were performed using borosilicate glass microelectrodes (3-5 M 2 ) containing (mM) K-gluconate, 130; $\mathrm{KCl}$, 20; K-Hepes, 10; EGTA, 0.2; Na-GTP, 0.3; MgATP, 4; pH 7.3, 287 mOsm. The aCSF was additionally supplemented with CNQX $(5 \mu \mathrm{M})$, AP5 $(5 \mu \mathrm{M})$, and picrotoxin $(50 \mu \mathrm{M})$ to block AMPA/kainate, NMDA, and $\mathrm{GABA}_{\mathrm{A}}$ receptors, respectively. The liquid junction potential of $13 \mathrm{mV}$ was corrected for arithmetically. Only cells with a corrected junction potential and a resting membrane potential more negative than $-60 \mathrm{mV}$ were used for experiments. To keep the pre-stimulus membrane potential at a set level of $-60 \mathrm{mV}$, the automatic slow current injection function of the MultiClamp 700B amplifier (5-s time constant) was used.

Evoked excitatory post-synaptic potentials (eEPSPs) were induced by electrical stimulation of Schaffer collaterals through a PI-Ir electrode and recorded in current-clamp mode with the membrane potential set to $-60 \mathrm{mV}$. For the measurements of the eEPSP, we used the following pipette solution (in $\mathrm{mM}$ ): K-gluconate 135, K-HEPES 10, $\mathrm{MgCl}_{2}$ 3.94, $\mathrm{Na}_{2}$ ATP 2, Na-GTP 0.2 , EGTA $0.010 ; \mathrm{pH} 7.27$, osmolarity $282 \mathrm{mOsm}$. (Calculated with "Ca Buf" program (G. Droogmans, KU Leuven), concentration of Mg-ATP was $1.94 \mathrm{mM}$ and free $\mathrm{Mg}^{2+}-2 \mathrm{mM}$.)

To determine the NMDA/AMPAR ratio, patch microelectrodes were filled with a solution containing (in $\mathrm{mM}$ ) $135 \mathrm{CsMeSO}_{4}, 4 \mathrm{NaCl}, 4 \mathrm{Mg}$-ATP, $0.3 \mathrm{Na}$-GTP, 0.5 EGTA, 10 K-HEPES; pH 7.24, 281 mOsm. Pipette resistance was 3-5 M $\Omega$. Excitatory post-synaptic currents (EPSCs) were evoked with biphasic square electric pulses delivered to Schaffer collaterals. AMPA-mediated EPSCs were measured at a holding potential of $-70 \mathrm{mV}$ in the 
presence of $100 \mu \mathrm{M}$ picrotoxin to block GABA(A) receptor-mediated inhibition. NMDA-mediated EPSCs were measured at $V_{\mathrm{h}}=+40 \mathrm{mV}$ in the presence of CNQX $(40 \mu \mathrm{M})$ and picrotoxin $(100 \mu \mathrm{M})$ to block AMPA- and $\mathrm{GABA}_{\mathrm{A}}$-mediated components, respectively.

In the pairing protocol, CA1 pyramidal neurons were patched with a pipette solution containing $135 \mathrm{mM}$ $\mathrm{CsMeSO}_{3}, 10 \mathrm{mM}$ HEPES, $8 \mathrm{mM} \mathrm{NaCl}, 0.3 \mathrm{mM}$

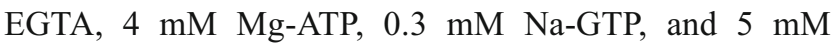
QX-314. LTP in CA1 pyramidal neurons was induced by pairing stimulation of Schaffer collaterals, for $90 \mathrm{~s}$ at $2 \mathrm{~Hz}$, with post-synaptic depolarization at a holding potential of $0 \mathrm{mV}$ in voltage-clamp mode [34]. Recordings were carried out at $25{ }^{\circ} \mathrm{C}$. Evoked EPSC amplitudes were normalized to baseline amplitudes prior to LTP induction on a cell-by-cell basis (i.e., \% of a base line mean).

\section{$\mathrm{Ca}^{2+}$ imaging}

After recovery, acute hippocampal slices were incubated at room temperature for $60 \mathrm{~min}$ in oxygenated aCSF, containing $1 \mu \mathrm{M}$ Fura2-AM (Biotium). Thereafter, they were placed in the recording chamber of an upright fluorescence microscope (Olympus Deutschland GmbH, Hamburg, Germany) and maintained at $37{ }^{\circ} \mathrm{C}$ using a heated (40×, water-immersion) objective and a temperature-controlled multichannel perfusion system. A concentric bipolar stimulation electrode (World Precision Instruments, Sarasota, USA) was positioned to stimulate Schaffer collateral afferent fibers. Changes in intracellular calcium were monitored in the proximal stratum radiatum (CA1 region). For excitation (at 350 and $380 \mathrm{~nm}$ ) of Fura-2, a Polychrome V monochromator (Till Photonics, Munich, Germany) was used. A 409-nm beamsplitter and a 510/590BP emission filter allowed detection of the fluorescent signal by a highspeed EM-CMOS camera (Andor iXON+ DU885KCS-VP, Andor Technology Ltd., Belfast UK). Regions of interest were selected, and analysis was performed with Live Acquisition (LA) Software from Till Photonics (Graefelfing, Germany). Fluorescence data was acquired at $2 \mathrm{~Hz}$ (illumination time $200 \mathrm{~ms}$ at each wavelength). For offline analysis and statistics, data was exported to Origin 7 software (Originlab, Northhampton, USA). For stimulation of Schaffer collaterals, biphasic pulse trains (duration $500 \mathrm{~ms}$ at $100 \mathrm{~Hz}, 1-\mathrm{ms}$ pulse width) were applied with an isolated pulse stimulator Model 2100 (A-M Systems, Sequim, USA) with increasing stimulation strengths of 50, 100, $200,300,400$, and $500 \mu \mathrm{A}$ given at a 75 -s interval. Synchronization between electrical stimulation and fluorescence recording was assured via the LA software (Till Photonics, Graefelfing, Germany), which triggered both the Polychrome $\mathrm{V}$ monochromator and the pulse stimulator, via Patchmaster software (HEKA, Harvard Bioscience Inc., USA) and an EPC9 amplifier (HEKA, Harvard Bioscience Inc., USA). For data analysis, three active regions of interests (ROI) were selected in the proximal stratum radiatum (CA1 region). The fluorescence intensities of these were averaged. Background correction was performed, by subtracting the fluorescence level, both for 350 and $380 \mathrm{~nm}$, from a nearby non-active region of the same size as the recording region, as measured in parallel. Results are presented as $\Delta F=F-F_{0} . F_{0}$ represents the averaged fluorescence ratio before the start of the stimulation train. Per mouse, at least two hippocampal slices were utilized. Four mice per genotype were used for experiments.

\section{Chemicals}

Nifedipine and isoprenaline were purchased from Sigma-Aldrich, CNQX and D-APV from Ascent Scientific (Bristol, UK), and picrotoxin and (S)-3,5-dihydroxyphenylglycine (DHPG) from Tocris Cookson (Bristol, UK).

\section{Statistical analysis}

Data are expressed as mean \pm SEM. Data were compared by two-tailed Student's $t$ test and repeated-measures ANOVA with Tukey's post hoc analysis. Statistical analyses were performed using Graphpad Prism 5 (GraphPad Software, Inc., La Jolla, CA, USA) and SPSS 19 (Armonk, NY, USA). Statistical significance was accepted at $p<0.05$.

\section{Results}

\section{TRPM4 is localized in the pyramidal cells of the hippocampal CA1 region}

We examined TRPM4 distribution in the mouse hippocampus by in situ hybridization and found TRPM4 mRNA expression in the granule cells of the dentate gyrus and pyramidal cells of the area CA1 and to a lesser extent in the CA3 pyramidal layer (Fig. 1a). Western blotting of plasma membrane-enriched lysates from hippocampus verified the presence of TRPM4 in WT but not in Trpm $4^{-/}$hippocampi (Fig. 1b).

For morphological characterization, we performed Golgi staining on the hippocampus. The apical dendrites of CA1 pyramidal neurons of WT and Trpm $4^{-/}$mice were not significantly different in total dendritic length and the number of branch points (Fig. 1d, e). We observed no significant differences in Sholl analysis or in spine density between the two genotypes (Fig. 1d-f).

The number of pyramidal neurons was not different between WT and Trpm $4^{-/}$, and the size of the cells in the 
a
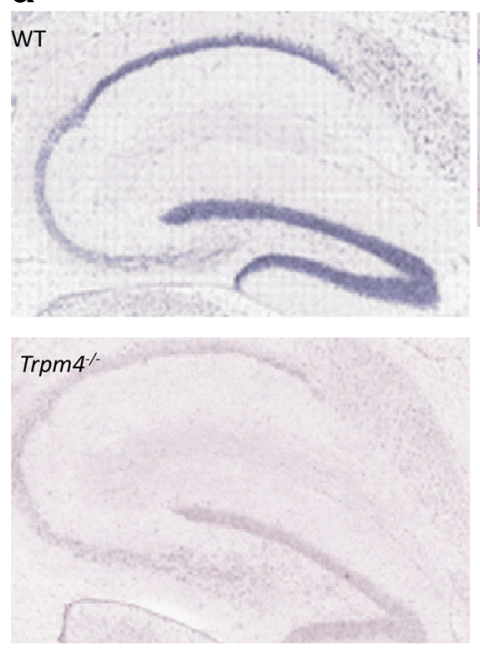

d

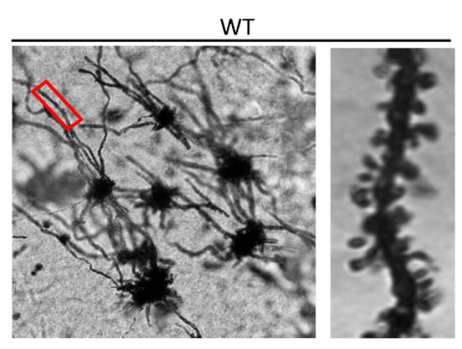

f

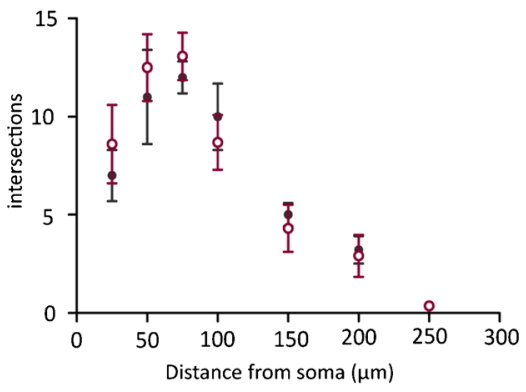

i

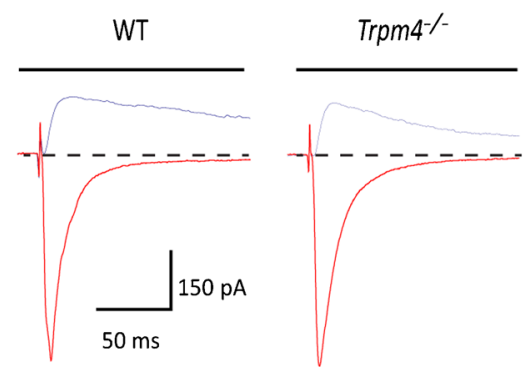

b

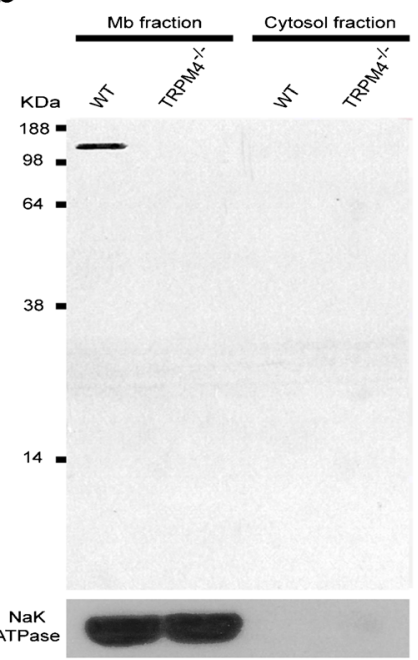

C
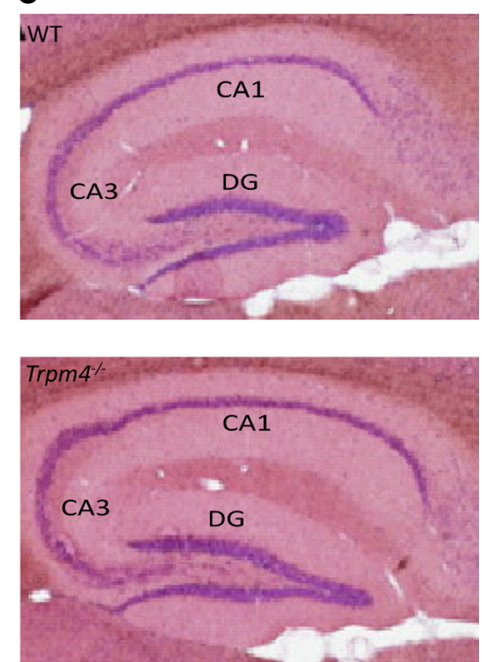

e
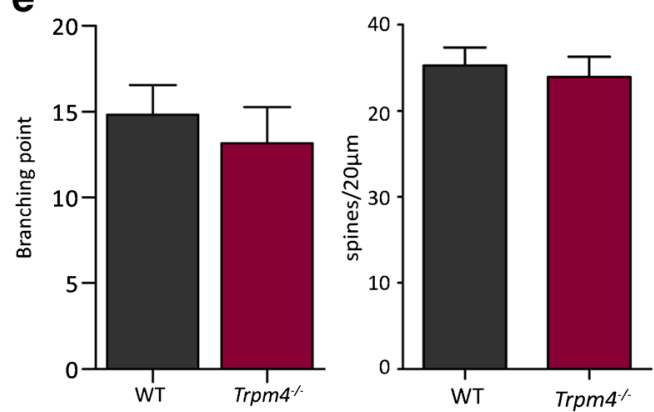

h

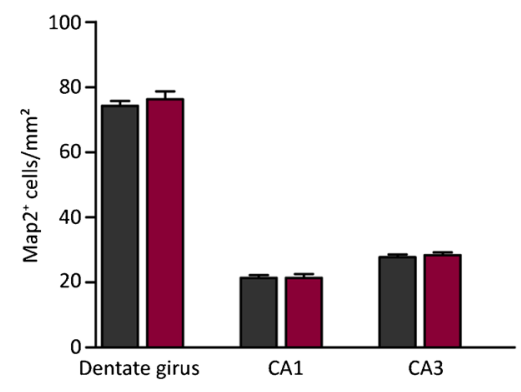

j
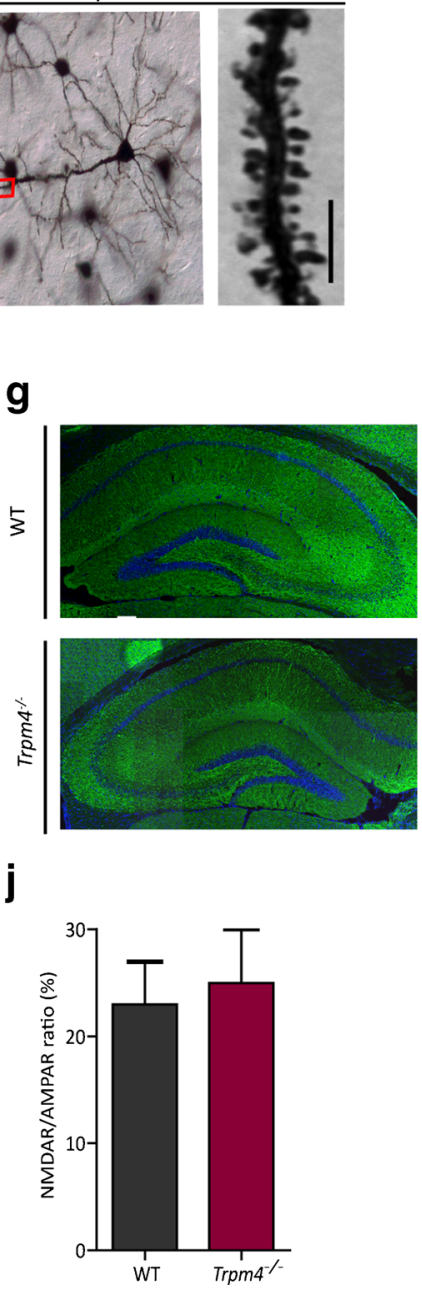

regions of the hippocampus where mRNA was abundant was comparable between WT and Trpm $4^{-/}$, as determined with MAP2 staining (cells $/ \mathrm{mm}^{2}$; DG WT 76.33 \pm 4.16 ; Trpm $4^{-/}$
$74.33 \pm 2.5$; CA1 WT $21.08 \pm 2.2 ;$ Trpm $^{-/-} 21.33 \pm 1.53$; CA3 WT $28.33 \pm 3.16$; $\operatorname{Trpm}^{-/} 27.67 \pm 1.88 ; N=5$ for both genotypes; Fig. 1 g, h). 
Fig. 1 Expression pattern of TRPM4, analysis of hippocampal morphology and NMDA/AMPA ratio. a In situ hybridization of TRPM4 mRNA in hippocampus from WT (upper panel) and Trpm $4^{-1-}$ (lower panel) mice. Higher magnification pictures of the CA1 dendritic area. b Western blotting using TRPM4 antibody confirmed the lack of expression of TRPM4 in membrane enriched lysates (lanes 1-2) from hippocampi of Trpm4 $4^{-/}$mice as compared to WT. Note the absence of expression in cytosolic fractions (lanes 3-4). c Hematoxylin and eosin staining of hippocampus coronal cryosections $(12 \mu \mathrm{m})$ from WT and $\mathrm{TRPM}^{-/}$mice. $\mathbf{d}$ Golgi staining of CA1 neurons from WT and Trpm $4^{-}$ neurons. Magnified view of apical dendritic segments from the stratum radiatum, as indicated by red boxes. The scale bar represents $5 \mu \mathrm{m}$. e, $\mathbf{f}$ Branching points, dendritic linear index (e), Sholl measurements (f) from WT and $\operatorname{Trpm}^{4^{-}}$CA1 neurons, derived from Golgi staining (as in d). $\mathbf{g}$ Mosaic imaging of MAP2 (green) and DAPI (blue) staining on dorsal hippocampus cryosection. $\mathbf{h}$ Density of MAP2-positive cells in dorsal hippocampus. $\mathbf{i}$ Representative traces of NMDA and AMPAR currents in WT and TRPM4 ${ }^{-/}$CA1 neurons. $\mathbf{j}$ The NMDAR/AMPAR current ratio as assessed at -70 and $+40 \mathrm{mV}$ is not significantly changed in $\operatorname{Trpm}^{{ }^{-/}}$CA1 neurons (WT $n=7 ; \operatorname{Trpm}^{4^{-}} n=9$ )

\section{TRPM4 deficiency does not impair basal glutamatergic neurotransmission}

To study a role of TRPM4 in synaptic communication and plasticity in the hippocampus, we focused on the Schaffer collateral-CA1 synapse, whose mechanisms are particularly well explored. Given the dominant role of glutamate receptors in these processes, we first tested AMPA and NMDA receptor activity and measured evoked EPSCs (eEPSCs) from CA1 pyramidal neurons using the whole-cell voltage-clamp technique. As shown in Fig. 1i, j, AMPA receptor-mediated eEPSCs recorded at post-synaptic membrane potentials of $-70 \mathrm{mV}$ (in the presence of $100 \mu \mathrm{M}$ picrotoxin) and NMDA receptormediated eEPSCs measured at $+40 \mathrm{mV}$ (in the presence of $40 \mu \mathrm{M}$ CNQX and $100 \mu \mathrm{M}$ picrotoxin) were identical between genotypes, excluding a shift in the ratio of NMDA to AMPA-mediated currents in Trpm $4^{-1-}$.

Subsequently, we checked by multi-electrode array recordings from acute hippocampal slices of WT and Trpm $4^{-1}$ mice whether the absence of TRPM4 protein affects the efficacy of basal synaptic transmission. As shown in Fig. 2a, the input/ output properties of field excitatory post-synaptic potentials (fEPSPs) were indistinguishable between WT and Trpm $4^{-1}$ slices. We also tested paired-pulse facilitation in CA1 neurons as a measure of short-term plasticity and did not detect any difference between WT and Trpm $4^{-/}$at all tested interpulse intervals (Fig. 2b).

\section{Trpm $4^{-/}$neurons exhibit deficits in NMDAR-dependent LTP}

To determine whether TRPM4 plays a role in long-term synaptic plasticity, we first examined the effect of low- frequency stimulation $(1 \mathrm{~Hz})$ on the Schaffer collateralCA1 synapses, which induces a NMDA receptordependent long-term depression (NMDAR-LTD) [10]. As shown in Fig. 2c, this conditioning protocol induced a long-lasting depression of fEPSPs that was maintained for at least $2 \mathrm{~h}$, and which was indistinguishable between both genotypes (WT $n=5$ mice; Trpm $4^{-/} n=5$ mice; $F_{(1,8)}=0.53, p=0.823$, RM-ANOVA). Likewise, mGluR-dependent LTD induced by bath application of the specific group I mGluR agonist DHPG was not different between WT and Trpm $4^{-/}$slices (WT $n=5$ mice; Trpm $4^{-/-} n=6$ mice; $F_{(1,9)}=2.336, p=0.161$, RM-ANOVA; Fig. 2d).

Next, we induced long-term potentiation by either 1 or 3 trains of theta-burst stimulation (TBS) and examined the effect on synaptic strength. As depicted in Fig. 2e, f, the initial magnitude of potentiation was significantly lower in Trpm $4^{-/}$mice. Furthermore, whereas 1 and 3 TBS induced a significant and long-lasting potentiation $(>2 \mathrm{~h})$ in WT, the same conditioning protocols evoked only a minimal, transient potentiation in $\operatorname{Trpm}^{-/}$slices (1 TBS WT $n=10$ mice; Trpm $4^{-/-} n=10$ mice; $F_{(1,18)}=53.869$,

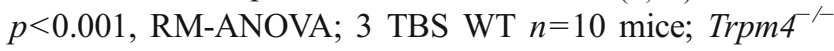
$n=10$ mice; $F_{(1,18)}=42.717, p<0.001$, RM-ANOVA).

Post-synaptically expressed LTP develops in two phases, the induction phase, which is dependent on NMDAR activation, and the expression phase, which is associated with phosphorylation and membrane insertion of AMPAR. In order to decipher whether the lack of LTP in Trpm $4^{-/-}$was due to a specific defect in the induction or the expression phase, we investigated the phosphorylation state of $\mathrm{Ca}^{2+} /$ calmodulin-dependent kinase II (CamKII), which is known to be the first step of the signaling cascade upon $\mathrm{Ca}^{2+}$ influx through NMDA receptors [21, 35]. While the phosphorylation level of the kinase increased after TBS stimulation in WT, no difference was detectable in $\operatorname{Trpm} 4^{-/-}$(Fig. 2g), supporting a TRPM4-dependent defect during the induction phase, before the activation of CamKII by $\mathrm{Ca}^{2+}$ influx through NMDA receptors.

In the next set of experiments, we tested whether increasing the stimulation strength above the level that is commonly used for LTP induction can restore LTP in Trpm $4^{-/}$slices. As shown in Fig. 2h, in response to 5 or 8 trains of TBS, significant long-term potentiation of the fEPSP was also apparent in Trpm $4^{-/-}$. Noticeably, however, the level of potentiation was significantly lower in $\operatorname{Trpm}^{-/-}$and already saturated at $5 \mathrm{TBS}$, while in WT slices, 8 TBS still evoked more potentiation than 5 TBS (Fig. 2f; 5 TBS WT vs Trpm $4^{-1-} F_{(1,9)}=6.763$, $p<0.01, n=6$ and 5, respectively, RM-ANOVA; 8 TBS WT vs Trpm $4^{-1} F_{(1,9)}=16.242, p<0.01, n=6$ and 5, respectively, RM-ANOVA). 

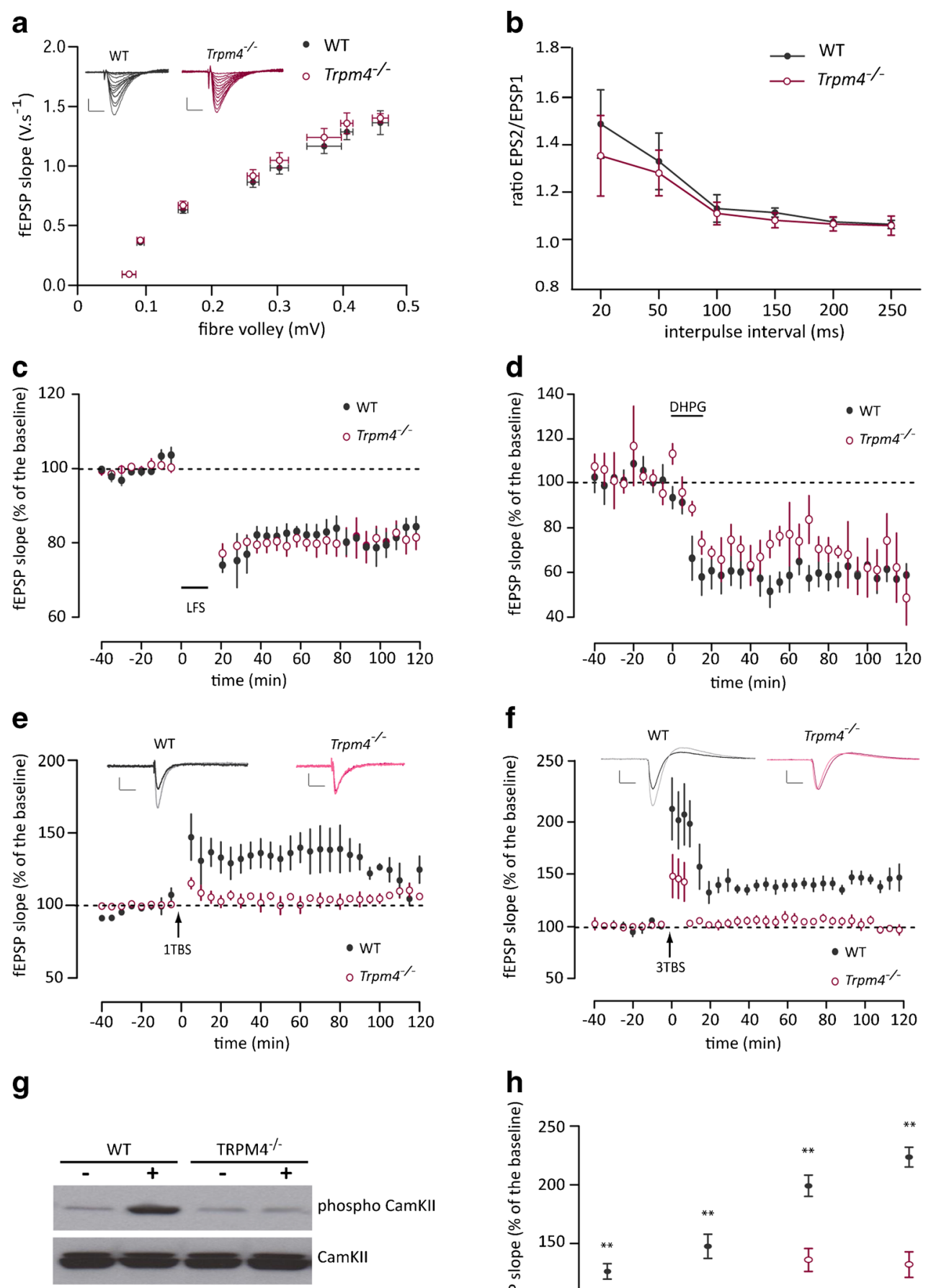

\section{Voltage-dependent $\mathrm{Ca}^{2+}$ channel-dependent potentiation is intact in $\mathrm{Trpm}^{4^{--}}$CA1 neurons}

Since an increasing number of TBS stimuli partially rescued the phenotype in Trpm $4^{-/}$neurons, we also tested highfrequency stimulation (HFS) at $100 \mathrm{~Hz}$. We used 2 trains of HFS to induce potentiation in WT and mutant slices. Although both WT and Trpm $4^{-/}$slices exhibited a long-lasting potentiation of at least $2 \mathrm{~h}$, the level of potentiation was significantly

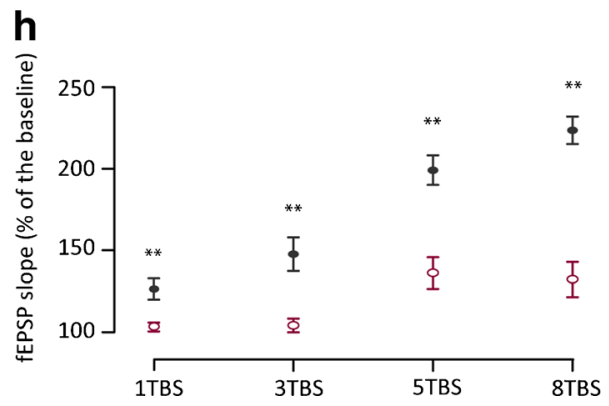

reduced in the Trpm $4^{-/-}$slices (Fig. 3a; WT $n=8$ mice; Trpm $4^{--} n=7$ mice; $F_{(1,13)}=16.062, p<0.05$, RM-ANOVA). Similar as found after TBS stimulation, CaMKII phosphorylation in $\operatorname{Trpm}^{4^{-/}}$slices was also impaired following HFS (Fig. 3b).

It has been reported that HFS induces a compound LTP, which is dependent on the activation of both the NMDARs and voltage-dependent $\mathrm{Ca}^{2+}$ channels (VDCC) $[5,13,15]$. To test whether the impaired potentiation in $\operatorname{Trpm}^{4^{-}}$could be 
4 Fig. 2 Normal basal transmission, short-term plasticity, and LTD but impaired LTP in Trpm $4^{-/}$hippocampal CA1 neurons. a Input/output curves of fEPSP slopes recorded from CA1 neurons at increasing stimulation intensities $(0.5-4 \mathrm{~V})$ did not differ between WT $(n=12)$ and Trpm $4^{--}(n=12)$. Representative analog traces are shown in the inset (calibration $5 \mathrm{~ms}, 0.35 \mathrm{mV}$ ). b Paired-pulse facilitation (PPF) at different stimulus intervals in WT and Trpm $4^{-/}$slices. (WT $n=14 ; \operatorname{Trpm} 4^{-/-}$ $n=12$ ). c NMDAR-dependent LTD induced by low-frequency stimulation applied at time " 0 ." No differences in the level of depression were detected between the two groups (WT $n=5 ; \operatorname{Trpm}^{-/} n=5$ ). $\mathbf{d ~ m G l u R -}$ dependent LTD induced by bath application of the group I mGluR agonist DHPG did not differ between genotypes (WT $n=5 ; \operatorname{Trpm}^{5^{-/}} n=6$ ). e NMDAR-dependent LTP was induced by 1 theta-burst stimulation (TBS 5 bursts of 4 pulses at $100 \mathrm{~Hz}$ repeated at 200-ms interval, pulse width $100 \mu \mathrm{s})$ in WT $(n=10)$ but not Trpm $4^{-1}(n=10)$. TBS was applied to the Schaffer collateral pathway at time " 0 ." Representative analog traces are shown in the inset (calibration $5 \mathrm{~ms}, 0.35 \mathrm{mV}$ ). $\mathbf{f}$ Three TBS evoked NMDAR-dependent LTP only in WT $(n=10)$ while recordings of $\operatorname{Trpm} 4^{-/}(n=10)$ returned to baseline immediately after conditioning. Representative analog traces are shown in the inset (calibration $5 \mathrm{~ms}$, $0.35 \mathrm{mV}$ ). $\mathbf{g}$ Lack of CamKII phosphorylation after a 3 TBS conditioning protocol in Trpm $4^{-/}$but not WT slices, detected by Western blotting of protein lysates from hippocampal CA1 region. $\mathbf{h}$ Changes in normalized fEPSP after different conditioning protocols $(1,3,5,8$ TBS) are represented in function of the induction protocol (5 TBS WT, $n=6$; TRPM4, $n=5, p=0.0287$; 8 TBS WT, $n=6$; TRPM4 ${ }^{-/}, n=5, p<0.01$; RMANOVA). Conditioning protocols were applied to the Schaffer collateral pathway at time " 0 "

due to a difference in activation of either of these pathways, we applied D-APV $(100 \mu \mathrm{M})$, a specific NMDAR blocker, and nifedipine $(100 \mu \mathrm{M})$, an L-type VDCC blocker prior to and during HFS stimulation. Application of D-APV reduced the level of potentiation in the WT while it had no effect in Trpm $4^{-/}$(WT control $n=8$ mice; APV $n=4$ mice; $p<0.05$ two-way ANOVA; Trpm $4^{-/}$control $n=8$ mice; APV $n=4$ mice; n.s two-way ANOVA) (Fig. 3c). In contrast, nifedipine application totally abolished LTP in Trpm $4^{-/}$and decreased potentiation in the WT group (WT control $n=8$ mice; nifedipine $n=5$ mice; $p<0.05$ two-way ANOVA; Trpm $4^{-/-}$control $n=8$ mice; nifedipine $n=5$ mice; $p<0.05$ two-way ANOVA) (Fig. 3d). These results, summarized in Fig. 3e, suggest that in Trpm $4^{-/}$, HFS-LTP is induced only through L-type VDCCmediated $\mathrm{Ca}^{2+}$ influx, i.e., in an NMDAR-independent manner.

\section{Reduced excitability of Trpm $4^{-/}$hippocampal CA1 neurons}

To examine the mechanism underlying the lack of LTP induction in CA1 neurons, we studied the electrophysiological properties of CA1 pyramidal cells in more detail, using whole-cell patch-clamp recordings. First, we analyzed miniature EPSPs (mEPSCs) and miniature IPSPs (mIPSCs) at Schaffer collateral CA1 synapses. We found no difference in the amplitude and frequency of mEPSCs and mIPSCs between WT and Trpm $4^{-/}$mice (mEPSCs amplitude WT
$11.01 \pm 0.88, n=6, \operatorname{Trpm}^{-/-} 10.67 \pm 0.31 n=6, p=0.7268, t$ test; mEPSC frequency WT $0.67 \pm 0.11 n=6$, Trpm $^{-/} 0.62$ $\pm 0.040 n=6, p=0.6843$; mIPSC amplitude WT $17.50 \pm$ $0.5216 n=6,16.91 \pm 0.71 n=6, p=0.5182$; mIPSC frequency WT $4.41 \pm 0.89 n=6, \operatorname{Trpm}^{-/-} 4.12 \pm 0.54 n=6, p=0.7818$ ). These data further support that there is no obvious defect in pre-synaptic release of exocytotic vesicles and basal synaptic transmission to CA1 principal cells. Subsequently, we compared the electrophysiological properties and stimulus-driven firing of CA1 neurons by measuring voltage responses to hyperpolarizing and depolarizing current injections $(-100$ and $+200 \mathrm{pA}$, respectively, for $500 \mathrm{~ms}$ ), applied at resting potential. As presented in Table $1, \operatorname{Trpm} 4^{-/-}$and WT mice did not differ in electrophysiological properties of CA1 neurons, such as resting membrane potential, input resistance, action potential amplitude, and amplitude of spike after-depolarization. Notably, the number of spikes during the depolarizing step was significantly lower in $\operatorname{Trpm}^{-/}$compared to WT mice (WT $12.3 \pm 0.82, n=12$ mice; $_{\text {Trpm }} 4^{-/} 9.9$ $\pm 0.79, n=6$ mice; $p=0.037$ Student's $t$ test) (Fig. 4a). Since also the half-width and time constant for relaxation of evoked EPSPs were significantly reduced in $\operatorname{Trpm}^{{ }^{-/}}$CA1 neurons, compared to WT neurons (Fig. 4b), this indicates that a depolarization-induced depolarizing current is reduced in Trpm $^{-1-}$ CA1 neurons, which contributes to the postsynaptic EPSP upon stimulation of Schaffer collaterals in WT hippocampal slices.

\section{Trpm $4^{-/}$hippocampal CA1 neurons lack a $\mathrm{Ca}^{2+}$-dependent cation current and show diminished $\mathrm{Ca}^{2+}$ transients}

To unveil TRPM4 channel activity in CA1 neurons directly, we performed whole-cell voltage-clamp measurements in the presence of a cocktail of blockers of glutamate receptors and voltage-gated $\mathrm{Ca}^{2+}, \mathrm{Na}^{+}$, and $\mathrm{K}^{+}$channels. To isolate a TRPM4-dependent component from the remaining background currents, we compared currents in response to a voltage ramp from -115 to $+35 \mathrm{mV}\left(V_{\mathrm{h}}=-85 \mathrm{mV}\right)$, in the absence or presence of high $\mathrm{Ca}^{2+}(10 \mu \mathrm{M})$ in the pipette solution. Such $\mathrm{Ca}^{2+}$ concentration is reached in spine heads in response to depolarization [30]. In these conditions, we found in $\operatorname{Trpm} 4^{+/+}$ CA1 neurons a $\mathrm{Ca}^{2+}$-dependent cation current with properties reminiscent of TRPM4 currents, such as $E_{\text {rev }}$ around $0 \mathrm{mV}$ and an outwardly rectifying $I-V$ relation [29] (Fig. 4c). As illustrated in Fig. 4d, this current increased in WT littermates in the high-intracellular $\mathrm{Ca}^{2+}$ condition by $51.5 \pm 19.6 \%$ as compared to the low-intracellular $\mathrm{Ca}^{2+}$ condition. This $\mathrm{Ca}^{2+}$-dependent cation current was absent in $\operatorname{Trpm}^{-/-} \mathrm{CA} 1$ neurons, resulting in current responses in the high-intracellular $\mathrm{Ca}^{2+}$ condition that were not significantly different from the background currents in the low-intracellular $\mathrm{Ca}^{2+}$ condition $(11.7 \pm$ 

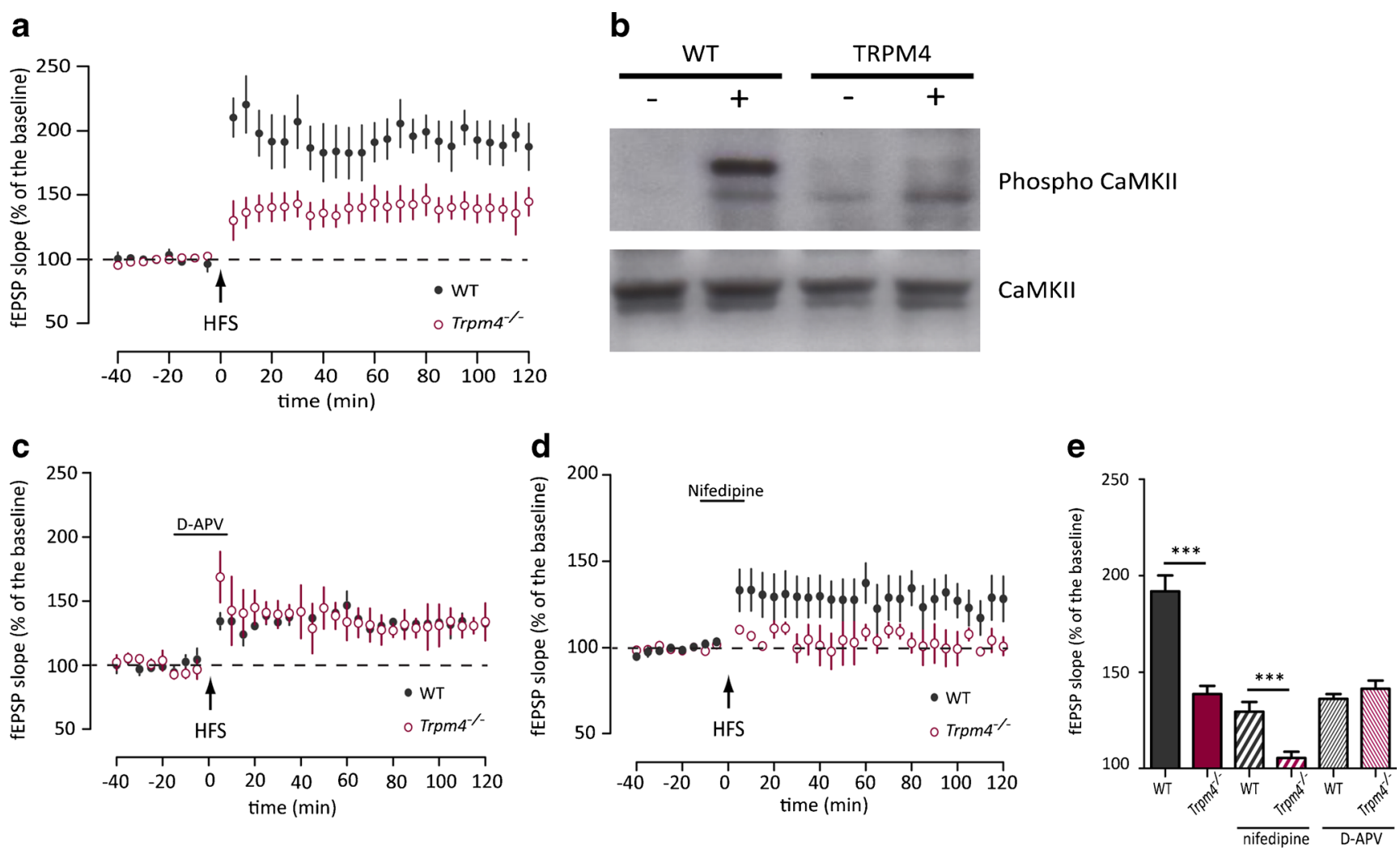

Fig. 3 HFS-LTP is inducible through activation of VDCC in $\operatorname{Trpm} 4^{-1}$ hippocampal neurons. a High-frequency stimulation (HFS 1-s burst at $100 \mathrm{~Hz}$ ) of the Schaffer collateral pathway induced stronger CA1 LTP in controls $(n=8)$ as compared to Trpm $4^{-/}$slices $(n=7)$. b Phosphorylation of CamKII before and after conditioning protocol (3 TBS) in WT and $\operatorname{Trpm} 4^{-/-}$slices detected by Western blotting of protein lysates from hippocampal CA1 region. c Application of $100 \mu \mathrm{M}$ of the NMDAR blocker D-APV reduced HFS-induced potentiation significantly in WT $(n=4)$ but not in $\operatorname{Trpm}^{-/}(n=4)$ LTP. d HFS-LTP in Trpm4 $4^{-\alpha}(n=5)$ was completely abolished by application of $100 \mu \mathrm{M}$ of VDCC blocker nifedipine while WT still showed a significant potentiation $(n=5)$. e Summary of the effects of D-APV and nifedipine on LTP in Trpm $4^{-/}$and WT
$10.3 \%, p=0.2724$, one-sample $t$ test; Fig. $4 \mathrm{~d}$, right bar graphs; Fig. 4c, d).

The above data suggest that TRPM4 contributes to postsynaptic depolarization of post-synaptic neurons upon stimulation of Schaffer collaterals, which is a critical step for full activation of NMDA receptors and initiation of LTP induction

Table 1 Basal electrophysiological properties of CA1 pyramidal neurons in acute slices of Trpm $4^{-/}$and WT mice

\begin{tabular}{lcc}
\hline & Wild-type & Trpm $^{-/}$ \\
\hline Resting $V_{\mathrm{m}}(\mathrm{mV})$ & $-70.7 \pm 1.04(23)$ & $-71.0 \pm 1.69(15)$ \\
Membrane time constant $(\mathrm{ms})$ & $25.4 \pm 1.99(21)$ & $28.9 \pm 2.54(11)$ \\
Input resistance $(\mathrm{M} \Omega)$ & $151 \pm 16(21)$ & $157 \pm 16(11)$ \\
AP amplitude $(\mathrm{mV})$ & $87.7 \pm 2.01(21)$ & $91.5 \pm 2.86(11)$ \\
AP width at 0 mV & $1.07 \pm 0.05(21)$ & $1.09 \pm 0.11(11)$ \\
\% sag & $20.5 \pm 3.3(21)$ & $21.2 \pm 2.5(11)$ \\
ADP amplitude $(\mathrm{mV})$ & $13.3 \pm 0.8(12)$ & $14.1 \pm 0.9(7)$ \\
\hline
\end{tabular}

Mean \pm SEM. $n$-Numbers are indicated in brackets and represent the number of cells. No significant differences were detected between WT and $\operatorname{Trpm} 4^{-1}$
[20]. Hence, deletion of TRPM4 is expected to diminish membrane depolarization and $\mathrm{Ca}^{2+}$ influx via NMDA receptors, which should be detectable by $\mathrm{Ca}^{2+}$ imaging as smaller $\mathrm{Ca}^{2+}$ transients as compared to WT controls. Therefore, we measured $\mathrm{Ca}^{2+}$ transients in the CA1 dendritic region in response to high-frequency stimulation applied at various stimulation intensities to Schaffer collaterals. As shown in Fig. 4e, f, at low stimulation intensities, there was no difference between WT and Trpm $4^{-/-}$CA1 neurons. However, at high stimulation intensities, as used for LTP induction (see Fig. 3a), $\mathrm{Ca}^{2+}$ levels are significantly lower in $\mathrm{Trpm} 4^{-/} \mathrm{CA} 1$ neurons compared to WT (Fig. 4e, f, RM-ANOVA, $p<0.01 ; F_{(1,7)}=30.4$ ).

\section{Rescue of impaired LTP by facilitating NMDAR activation and membrane depolarization}

If TRPM4 activity is necessary for NMDA receptor opening, facilitation of NMDA receptor opening or applying a postsynaptic depolarization should rescue the lack of LTP induction in $\operatorname{Trpm}^{-/}$slices. Such a rescue was achieved by increasing the excitability of Trpm $4^{-1}$ CA1 neurons via application of the $\beta$-adrenergic agonist isoprenaline $(10 \mu \mathrm{M}$; 
a

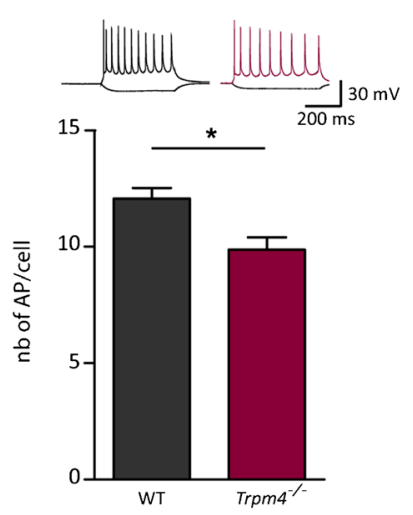

C

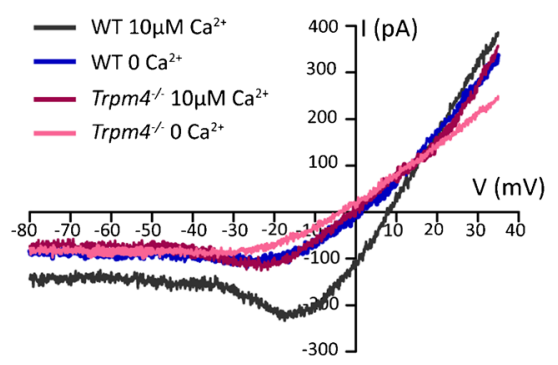

e

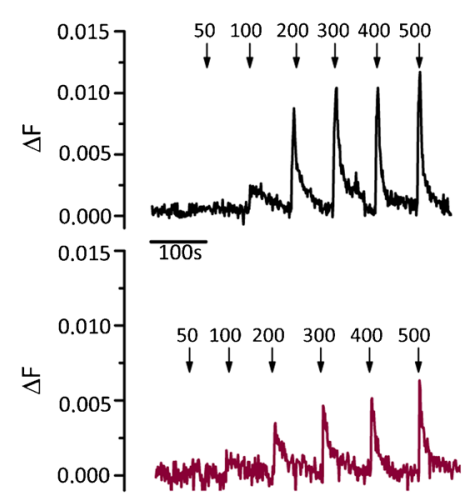

b

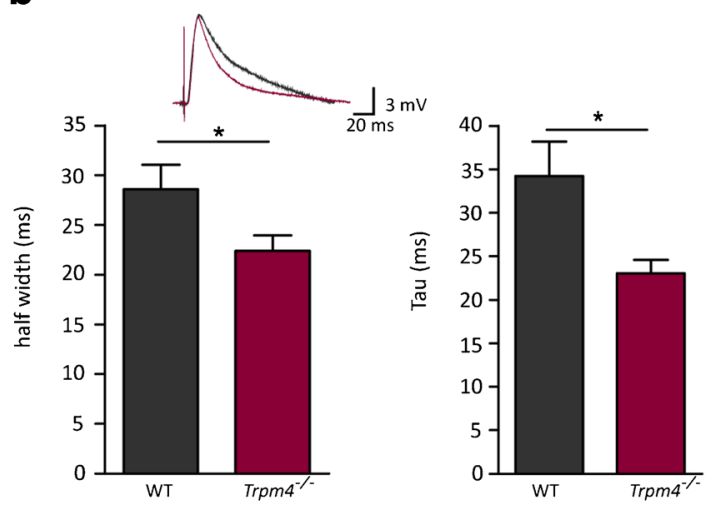

d

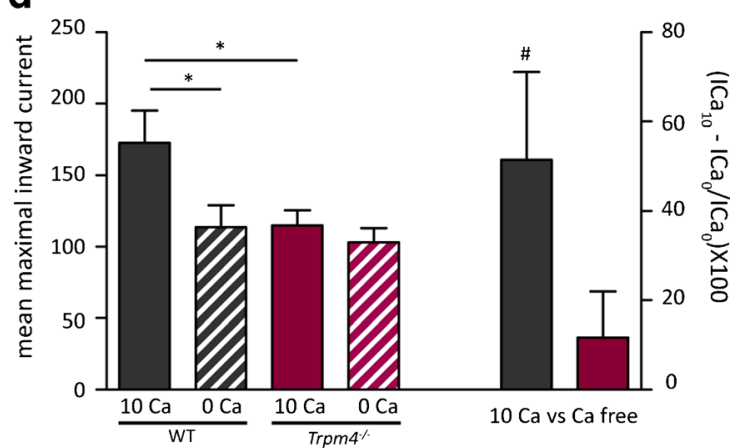

f

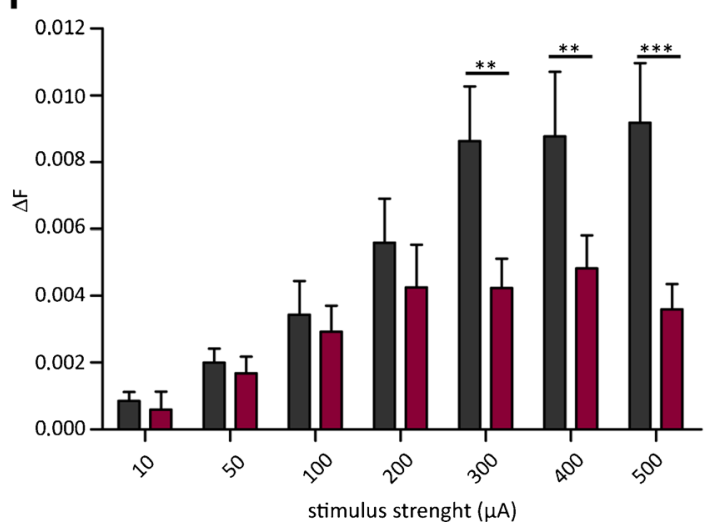

Fig. 4 Reduced excitability of CA1 neurons in $\operatorname{Trpm} 4^{-/-}$mice. a The number of CA1 action potentials evoked by depolarizing pulses of + $200 \mathrm{pA}$ for $500 \mathrm{~ms}$ was significantly reduced in $\operatorname{Trpm}^{-/} \quad(n=6)$ compared to WT mice $(n=12)(p=0.037$ Student's $t$ test; representative traces are shown above). b Half-width and relaxation time constant of evoked EPSCs were significantly reduced in $\operatorname{Trpm} 4^{-/}$neurons $(n=12$; WT $\left.n=10,{ }^{*} p<0.05\right)$. c Representative current traces in response to a voltage ramp from -115 to $+35 \mathrm{mV}\left(V_{\mathrm{h}}=-85 \mathrm{mV}\right)$. Currents are depicted in the presence of high free $\mathrm{Ca}^{2+}(10 \mu \mathrm{M})$ in the pipette solution or in $\mathrm{Ca}^{2+}$-free pipette solution, respectively. $\mathbf{d}$ Left bars Mean maximal inward current in CA1 hippocampal neurons from current traces as in panel c; right bars Percent increase in the TRPM4 current with $10 \mu \mathrm{M} \mathrm{Ca}^{2+}$ pipette solution as compared to the $\mathrm{Ca}^{2+}$-free condition $\left(\operatorname{Trpm~}^{-/-} n=12\right.$; WT $\left.n=11,{ }^{*} p<0.05\right)$. WT CA1 neurons show a significant current increase ( $\# p=0.0208$, one-sample $t$ test), in contrast to $\operatorname{Trpm} 4^{-/}$neurons $(p=0.2724)$. e Representative $\mathrm{Ca}^{2+}$ transients in the CA1 dendritic layer from WT and Trpm $4^{-/}$hippocampal slices. Stimuli $(500 \mathrm{~ms}, 100 \mathrm{~Hz})$ where applied at various stimulus intensities as indicated by arrowheads $\left(\Delta F=F-F_{0}\right)$. f Statistical analysis of peak $\mathrm{Ca}^{2+}$ signals derived from traces as in panel e $\left(\operatorname{Trpm}^{-/-} n=12\right.$; WT $n=$ 10, RM-ANOVA with Tukey's post hoc test)
Fig. 5a, b) Previous reports described that isoprenaline rescues a lack of TBS-induced LTP in mice with a C-terminally truncated GluN2A subunit [26], likely by inhibiting the A-type $\mathrm{K}^{+}$ current in CA1 neurons and thus facilitating depolarization. In our hands, isoprenaline completely restored the induction of 1 TBS-LTP in Trpm $4^{-/}$slices (Fig. 5a, b; Trpm $4^{-/}$untreated $n=10$ mice; $\operatorname{Trpm}^{4^{-}}$isoprenaline $n=7$ mice; Bonferroni's multiple comparison $t=8.322 p<0.0005$ ). In a second independent approach, we postulated that the LTP deficit should be overcome if the intrinsic depolarization is bypassed by using a pairing protocol for LTP induction under whole-cell patch-clamp conditions (similar as in [34]). This protocol 
Fig. 5 Facilitating NMDAR opening or post-synaptic depolarization rescues LTP induction in Trpm $4^{-/}$CA1 hippocampal neurons. a Potentiation induced with 1 TBS was rescued in $\operatorname{Trpm}^{-/}(n=7)$ by the presence $10 \mu \mathrm{M}$ isoprenaline. $\mathbf{b}$ Comparison of mean potentiation in untreated slices and in the presence of isoprenaline during the first hour of potentiation. c When the same post-synaptic depolarization was imposed on Trpm $4^{-/}$and WT CA1 neurons by a pairing protocol, similar robust LTP was obtained (WT $n=5$; $\left.\operatorname{Trpm} 4^{-/} n=6\right)$. d Representative analog traces of EPSCs before and after induction of LTP of a WT and Trpm $4^{-/}$neuron, as in panel c a

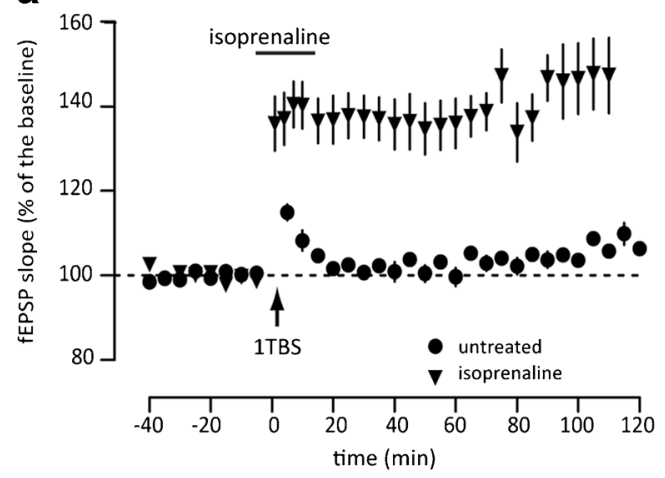

b

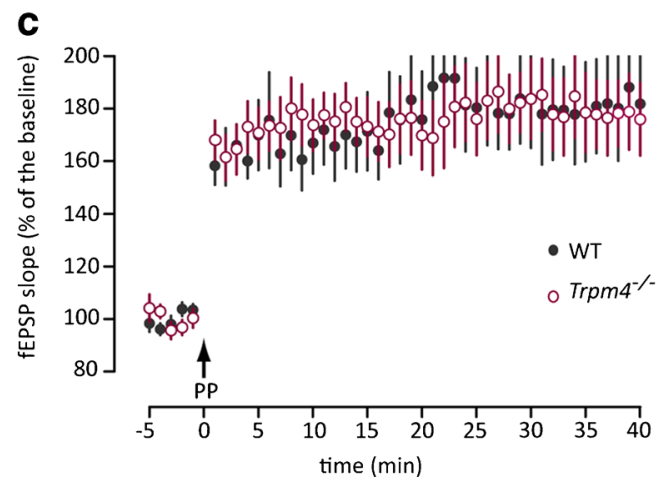

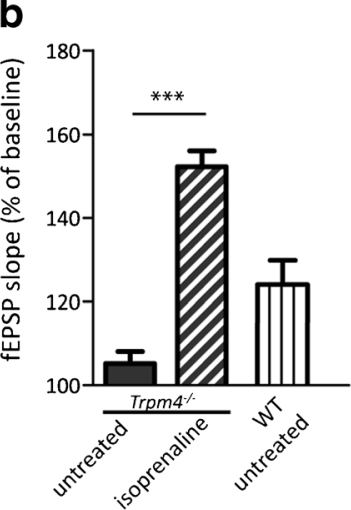

d
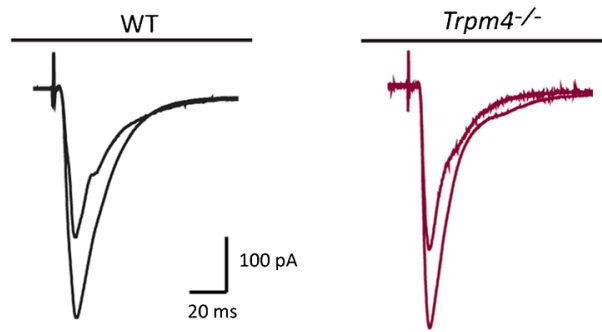

imposes the same post-synaptic depolarization upon CA1 neurons of both genotypes. Indeed, as depicted in Fig. 5c, d, LTP induced by this pairing protocol was similar for both genotypes (WT $n=6$ mice; Trpm $4^{-/-} n=5$ mice; $F_{(1,22)}=$ $0.004, p=0.947$, RM-ANOVA). Thus, these data strongly support the hypothesis that the LTP defect is caused by a lack of sufficient post-synaptic depolarization in response to TBS or HFS stimulation.

\section{Discussion}

In this study, we took advantage of Trpm 4 knockout mice [37] to provide the first direct evidence for a function of TRPM4, and $\mathrm{Ca}^{2+}$-activated non-selective cation channels in general, in neurons. Through in situ hybridization and western blotting, we show that TRPM4 is expressed in the CA1 region and the dentate gyrus of the hippocampus and to a lesser extent also in CA3 pyramidal neurons. While Trpm $4^{-1}$ mice are normal with regard to morphology, basal synaptic transmission, and paired-pulse facilitation at CA3-CA1 synapses, we found a complete lack of LTP induced by common theta-burst protocols to Schaffer collateral fibers. When high-intensity protocols were applied, such as 5-8 trains of theta-burst stimulation or 2 trains of high-frequency stimulation (HFS) at $100 \mathrm{~Hz}, \operatorname{Trpm}^{-/}$CA1 neurons developed LTP but to a lesser level than WT neurons. In contrast to LTP, NMDAR- and
mGluR-dependent LTD in CA1 neurons were unchanged in $\mathrm{Trpm}^{4^{-/}}$mice. Together, these data indicate that deletion of Trpm4 leads specifically to an increase in the threshold for LTP induction, without affecting the requirements for induction of LTD. Patch-clamp experiments showed that AMPA and NMDA receptor currents and their ratio are indistinguishable between WT and Trpm $4^{-/}$CA1 neurons, excluding changes in the activity or expression of these receptors as a reason for the observed phenotype. Instead, our data indicate an essential function of TRPM4 in the generation of a depolarizing current that is sufficiently strong to fully unblock NMDA receptors as mandatory condition for the induction of LTP. Accordingly, we have identified a $\mathrm{Ca}^{2+}$-dependent cation current in CA1 pyramidal neurons, which is absent in $\operatorname{Trpm} 4^{-/}$ mice. The lack of TRPM4 proteins leads to a reduced length of evoked excitatory post-synaptic currents and reduced excitability in CA1 neurons. Moreover, $\mathrm{Ca}^{2+}$ signals in CA1 neurons upon electrical stimulation of Schaffer collaterals are reduced in $\operatorname{Trpm} 4^{-/}$neurons compared to WT, which is consistent with a reduction of $\mathrm{Ca}^{2+}$ influx due to incomplete recruitment of NMDA receptors in Trpm $4^{-/}$mice. Consistent with the idea of insufficient post-synaptic depolarization as underlying cause of the observed LTP deficit, this phenotype can be completely rescued by application of isoprenaline, i.e., an intervention that facilitates the post-synaptic depolarization of CA1 neurons. Most convincingly, when the depolarization of $\operatorname{Trpm}^{-/}$neurons is artificially clamped to the same voltage as WT neurons 
during a pairing protocol, LTP in both genotypes is indistinguishable with respect to amplitude and time course.

Taken together, our data are consistent with a novel mechanistic model of LTP induction at Schaffer collateral-CA1 synapses in hippocampal slices, in which TRPM4 acts as an amplifier of the post-synaptic depolarization, which is indispensable to fully unblock the NMDA receptor and to initiate the induction of LTP in CA1 hippocampal neurons. As summarized in Fig. 6, we propose that in WT hippocampal CA1 neurons, the initial TBS stimulation leads to AMPA receptormediated depolarization of the post-synaptic membrane, which partially relieves the $\mathrm{Mg}^{2+}$ block of NMDA receptors. The resulting $\mathrm{Ca}^{2+}$ influx into the post-synaptic neuron activates TRPM4, which mediates a depolarizing current that further depolarizes the post-synaptic membrane, thereby fully unblocking NMDA receptors. Thus, TRPM4 activity facilitates NMDAR gating to a level necessary for activation of crucial plasticity-related downstream signal transduction

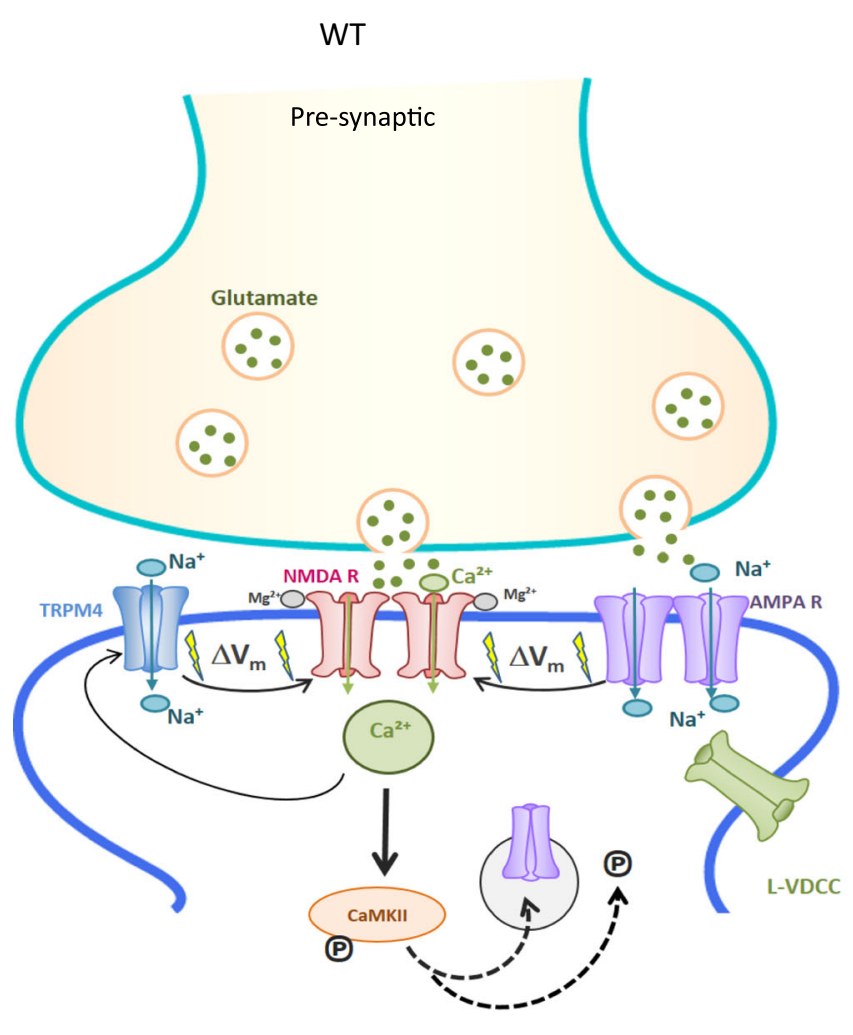

Post-synaptic

Fig. 6 Putative function of TRPM4 in LTP induction. Pre-synaptic glutamate release causes membrane depolarization $\left(\Delta V_{\mathrm{m}}\right)$ via activation of AMPA receptors (AMPAR). This depolarization triggers $\mathrm{Ca}^{2+}$ influx through L-type voltage-dependent calcium channels (L-VDCC) and NMDA receptors (after the $\mathrm{Mg}^{2+}$ block at the channel pore of NMDA receptors is relieved by depolarization), depending on the conditioning protocol. The initial depolarization and the rise of $\left[\mathrm{Ca}^{2+}\right]_{i}$ activates TRPM4 which leads to further membrane depolarization which fully unblocks the NMDAR. The resulting large intracellular calcium increase triggers phosphorylation of $\mathrm{Ca}^{2+} /$ calmodulin-dependent kinase II cascades. In the absence of TRPM4, activation of NMDA receptors is insufficient to properly induce LTP and the downstream signaling mechanisms. In this model, it is not surprising that the reduced post-synaptic depolarization in Trpm $4^{-/}$ CA1 neurons is sufficient to induce NMDA receptordependent LTD. At resting membrane potential, the $\mathrm{Mg}^{2+}$ block of NMDARs is incomplete allowing still a substantial $\mathrm{Ca}^{2+}$ influx which is sufficient to trigger the downstream signaling pathways that mediate LTD [30]. Moreover, recent work suggested that in young animals, LTD can be induced without any $\mathrm{Ca}^{2+}$ influx through NMDA receptors [28].

The lack of a substantial NMDAR-mediated component of potentiation during strong stimulation and the apparent reduction to a VDCC-mediated LTP-component in $\operatorname{Trpm} 4^{-/}$CA1 neurons is likely to have far-reaching consequences on $\mathrm{Ca}^{2+}$ dependent signaling cascades and gene activation. The ability of calcium influx to induce these events varies according to its amplitude, duration, and location $[14,30]$. Whereas opening

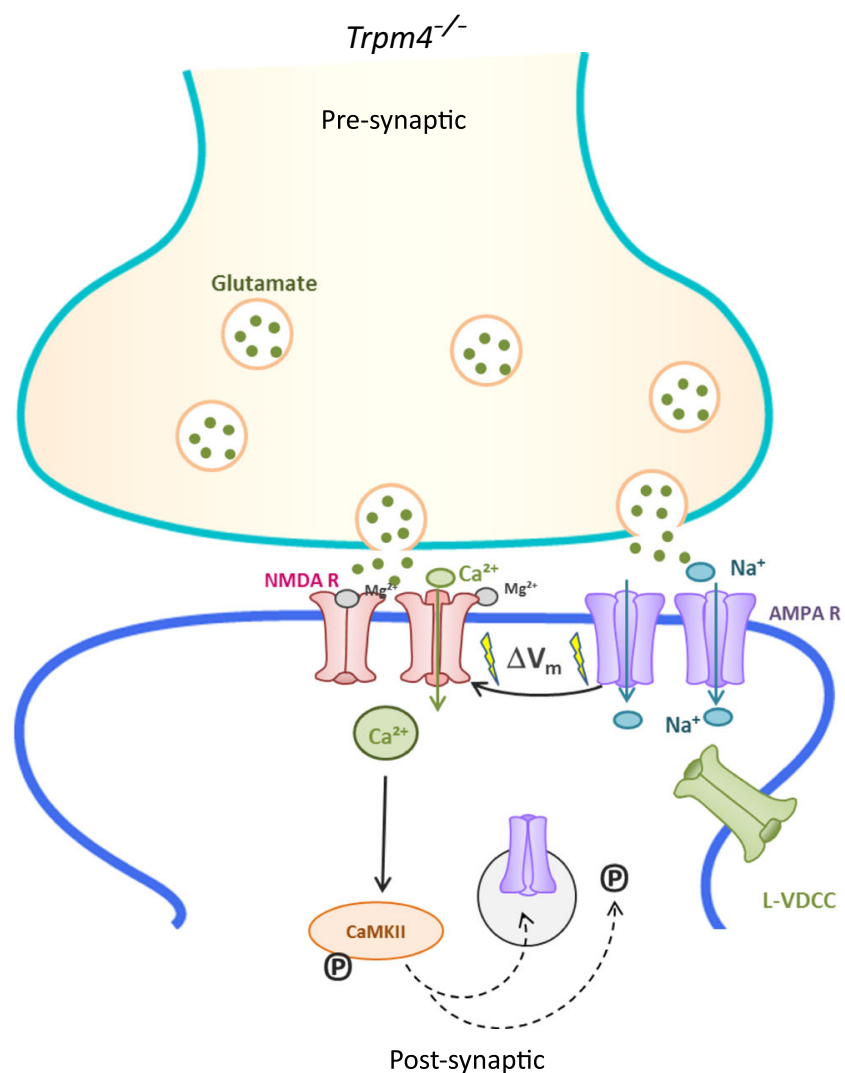

(CamKII), which in turn leads to phosphorylation of inserted AMPAR and insertion of new AMPAR into the synaptic membrane. Together, this results in the induction of robust LTP. In $\operatorname{Trpm} 4^{-/-}$mice, the lack of TRPM4-mediated depolarization causes only a partial removal of the magnesium block of NMDAR and a reduced calcium influx via this channel, which is insufficient to trigger LTP in Trpm $4^{-1}$ mice. Facilitating NMDAR activation (with serine), reducing the inhibitory tone via the A-current (ß-adrenergic stimulation), or additional depolarization of the post-synaptic membrane in a pairing protocol rescues the induction of LTP in Trpm $4^{-/}$mice (see the text for further details) 
of NMDARs leads primarily to relatively long-lasting $\mathrm{Ca}^{2+}$ influx into dendritic spines, $\mathrm{Ca}^{2+}$ influx via VDCC was found to be short-lived and sensed by a multiprotein complex in the vicinity of the VDCCs that contains calmodulin and CaMKII $[9,38]$. On the other hand, L-type VDCC subtypes $\left(\mathrm{Ca}_{\mathrm{v}} 1.1\right.$. and $\left.\mathrm{Ca}_{\mathrm{v}} 1.2\right)$ bind calmodulin at carboxy-terminal recognition sites [14] enabling calmodulin to sense elevated $\mathrm{Ca}^{2+}$ in microdomains in the immediate vicinity [30] and to mediate the activation of signaling cascades such as the ERK/MAPK and PKA pathways, respectively $[9,39]$.

TRPM4 and TRPM5 are to date the only molecular candidates for the class of $\mathrm{Ca}^{2+}$-activated non-selective cation channels [23]. Recently, it was shown that TRPM5, but not TRPM4, contributes to slow after-depolarizations in mouse prefrontal cortex neurons [18]. Others reported that TRPM4 and TRPM5 contribute to, but are not absolutely required for, depolarization-induced slow currents in cerebellar Purkinje cells [16]. While these studies described the involvement of TRPM4 in intrinsic neuronal properties by single-cell recording, the function of TRPM4 in specific neuronal tasks and in synaptic plasticity remained unclear. Previous studies have suggested a physiological role of TRPM4 in close functional relation with glutamate receptors $[8,25,27]$. The most investigated example is the process of burst firing in the pre-Bötzinger complex neurons [8] where TRPM4-like currents have been proposed to be responsible for amplifying glutamatergic synaptic drive, by transforming the glutamatergic synaptic inputs to long-lasting membrane depolarization [25]. Mrejeru et al. have described a similar mechanism in dopaminergic (DA) neurons of substantia nigra [27]. It was shown that in those neurons, NMDA currents recruit a $\mathrm{Ca}^{2+}$-activated non-selective current, which can be blocked by non-specific TRPM4 blockers such as flufenamic acid and 9-phenanthrol. Using Trpm $4^{-1}$ mice, Schattling et al. proposed a pathophysiological role for TRPM4 in glutamate stress-induced neurodegeneration [31]. Glutamate stress is an element of the pathophysiology of experimental autoimmune encephalopathy and multiple sclerosis, which is responsible for neuronal cell death and contributes to the progressive loss of motor functions during this condition. Trpm $4^{-1}$ mice are partly resistant to the development of EAE, specifically because $\operatorname{Trpm}^{4^{-/}}$neurons are resistant to cell death induced by glutamate overstimulation [31]. Our data suggest that the higher resistance of $\operatorname{Trpm}^{4^{-1}}$ neurons is likely to be caused (at least in part) by reduced $\mathrm{Ca}^{2+}$ influx through NMDA receptors upon glutamate stress leading to a decrease of $\mathrm{Ca}^{2+}$-induced neurotoxicity. Several other TRP channels are highly expressed in the brain, and some TRP channels, most notably TRPV1, have been proposed to participate in mechanisms of synaptic plasticity in the central nervous system (CNS)[36]. However, their roles in synaptic plasticity are a matter of debate (see for instance $[6,12$, 22], but also [4]).

In conclusion, our data highlight TRPM4 as a key mediator for NMDAR-mediated types of LTP while it does not seem to have a function in LTD induction. Our data support a mechanism in which $\mathrm{Ca}^{2+}$ influx through NMDA receptors and membrane depolarization trigger the activation of TRPM4, which further amplifies membrane depolarization via a TRPM4-mediated $\mathrm{Ca}^{2+}$-dependent cation current in order to fully unblock NMDA receptors.

Acknowledgments We thank all members of the Laboratory of Ion Channel Research (KU Leuven) for the helpful discussions. This work was supported by FWO Vlaanderen (G.0761.10N, G.0596.12, G.0565.07, G.0A14.14N), IUAP program from the Belgian Federal Government (P7/13), KU Leuven "Bijzonder Onderzoeksfonds" (STRT1/09/ 046, GOA 2009/07, GOA 12/008, EF/95/010, and TRPLe).

Authors' contributions AM, TA, VS, and KP performed the experiments and analyzed the data. MF and RV created the Trpm $4^{-1}$ mice. AS, $\mathrm{SP}$, and SK provided the technical support. TV, BN, RV, and DB initiated and supervised the study. RV and DB designed experiments and analyzed data. AM, RV, and DB wrote the manuscript.

Compliance with ethical standards All animal experiments were in accordance with the European Community Council Directive (86/609/ EC) and approved by the local ethics committee.

Competing interests The authors declare that they have no competing interests.

Open Access This article is distributed under the terms of the Creative Commons Attribution 4.0 International License (http:// creativecommons.org/licenses/by/4.0/), which permits unrestricted use, distribution, and reproduction in any medium, provided you give appropriate credit to the original author(s) and the source, provide a link to the Creative Commons license, and indicate if changes were made.

\section{References}

1. Ascher P, Nowak L (1988) The role of divalent cations in the Nmethyl-D-aspartate responses of mouse central neurones in culture. J Physiol 399:247-266

2. Bliss TV, Lomo T (1973) Long-lasting potentiation of synaptic transmission in the dentate area of the anaesthetized rabbit following stimulation of the perforant path. J Physiol 232:331-356

3. Bloodgood BL, Sabatini BL (2008) Regulation of synaptic signalling by postsynaptic, non-glutamate receptor ion channels. J Physiol 586:1475-1480

4. Cavanaugh DJ, Chesler AT, Jackson AC, Sigal YM, Yamanaka H, Grant R, O'Donnell D, Nicoll RA, Shah NM, Julius D, Basbaum AI (2011) Trpv1 reporter mice reveal highly restricted brain distribution and functional expression in arteriolar smooth muscle cells. J Neurosci 31:5067-5077

5. Cavus I, Teyler T (1996) Two forms of long-term potentiation in area CA1 activate different signal transduction cascades. J Neurophysiol 76:3038-3047 
6. Chavez AE, Chiu CQ, Castillo PE (2010) TRPV1 activation by endogenous anandamide triggers postsynaptic long-term depression in dentate gyrus. Nat Neurosci 13:1511-1518

7. Citri A, Malenka RC (2008) Synaptic plasticity: multiple forms, functions, and mechanisms. Neuropsychopharmacology 33:18-41

8. Crowder EA, Saha MS, Pace RW, Zhang H, Prestwich GD, Del Negro CA (2007) Phosphatidylinositol 4,5-bisphosphate regulates inspiratory burst activity in the neonatal mouse preBotzinger complex. J Physiol 582:1047-1058

9. Dolmetsch RE, Pajvani U, Fife K, Spotts JM, Greenberg ME (2001) Signaling to the nucleus by an L-type calcium channelcalmodulin complex through the MAP kinase pathway. Science 294:333-339

10. Dudek SM, Bear MF (1992) Homosynaptic long-term depression in area CA1 of hippocampus and effects of N-methyl-D-aspartate receptor blockade. Proc Natl Acad Sci U S A 89:4363-4367

11. Gees M, Owsianik G, Nilius B, Voets T (2012) TRP channels. Compr Physiol 2:563-608

12. Gibson HE, Edwards JG, Page RS, Van Hook MJ, Kauer JA (2008) TRPV1 channels mediate long-term depression at synapses on hippocampal interneurons. Neuron 57:746-759

13. Grover LM, Teyler TJ (1990) Two components of long-term potentiation induced by different patterns of afferent activation. Nature 347:477-479

14. Halling DB, Georgiou DK, Black DJ, Yang G, Fallon JL, Quiocho FA, Pedersen SE, Hamilton SL (2009) Determinants in CaV1 channels that regulate the $\mathrm{Ca} 2+$ sensitivity of bound calmodulin. J Biol Chem 284:20041-20051

15. Huber KM, Mauk MD, Kelly PT (1995) Distinct LTP induction mechanisms: contribution of NMDA receptors and voltagedependent calcium channels. J Neurophysiol 73:270-279

16. Kim YS, Kang E, Makino Y, Park S, Shin JH, Song H, Launay P, Linden DJ (2013) Characterizing the conductance underlying depolarization-induced slow current in cerebellar Purkinje cells. J Neurophysiol 109:1174-1181

17. Launay P, Fleig A, Perraud AL, Scharenberg AM, Penner R, Kinet JP (2002) TRPM4 is a Ca2+-activated nonselective cation channel mediating cell membrane depolarization. Cell 109:397-407

18. Lei Y-T, Thuault S, Launay P, Margolskee R, Kandel E, Siegelbaum S (2014) Differential contribution of TRPM4 and TRPM5 nonselective cation channels to the slow afterdepolarization in mouse prefrontal cortex neurons. Front Cell Neurosci 8

19. Leuner B, Falduto J, Shors TJ (2003) Associative memory formation increases the observation of dendritic spines in the hippocampus. J Neurosci 23:659-665

20. Lynch MA (2004) Long-term potentiation and memory. Physiol Rev 84:87-136

21. Malenka RC, Kauer JA, Perkel DJ, Mauk MD, Kelly PT, Nicoll RA, Waxham MN (1989) An essential role for postsynaptic calmodulin and protein kinase activity in long-term potentiation. Nature 340:554-557

22. Marsch R, Foeller E, Rammes G, Bunck M, Kossl M, Holsboer F, Zieglgansberger W, Landgraf R, Lutz B, Wotjak CT (2007) Reduced anxiety, conditioned fear, and hippocampal long-term potentiation in transient receptor potential vanilloid type 1 receptordeficient mice. J Neurosci 27:832-839

23. Mathar I, Jacobs G, Kecskes M, Menigoz A, Philippaert K, Vennekens R (2014) TRPM4. Handb Exp Pharmacol

24. Mayer ML, Westbrook GL, Guthrie PB (1984) Voltage-dependent block by $\mathrm{Mg} 2+$ of NMDA responses in spinal cord neurones. Nature 309:261-263
25. Mironov SL (2008) Metabotropic glutamate receptors activate dendritic calcium waves and TRPM channels which drive rhythmic respiratory patterns in mice. J Physiol 586:2277-2291

26. Moody TD, Watabe AM, Indersmitten T, Komiyama NH, Grant SG, O'Dell TJ (2011) Beta-adrenergic receptor activation rescues theta frequency stimulation-induced LTP deficits in mice expressing C-terminally truncated NMDA receptor GluN2A subunits. Learn Mem 18:118-127

27. Mrejeru A, Wei A, Ramirez JM (2011) Calcium-activated non-selective cation currents are involved in generation of tonic and bursting activity in dopamine neurons of the substantia nigra pars compacta. J Physiol 589:2497-2514

28. Nabavi S, Kessels HW, Alfonso S, Aow J, Fox R, Malinow R (2013) Metabotropic NMDA receptor function is required for NMDA receptor-dependent long-term depression. Proc Natl Acad Sci U S A 110:4027-4032

29. Nilius B, Prenen J, Droogmans G, Voets T, Vennekens R, Freichel M, Wissenbach U, Flockerzi V (2003) Voltage dependence of the Ca2+-activated cation channel TRPM4. J Biol Chem 278:3081330820

30. Sabatini BL, Oertner TG, Svoboda K (2002) The life cycle of $\mathrm{Ca}(2+)$ ions in dendritic spines. Neuron 33:439-452

31. Schattling B, Steinbach K, Thies E, Kruse M, Menigoz A, Ufer F, Flockerzi V, Bruck W, Pongs O, Vennekens R, Kneussel M, Freichel M, Merkler D, Friese MA (2012) TRPM4 cation channel mediates axonal and neuronal degeneration in experimental autoimmune encephalomyelitis and multiple sclerosis. Nat Med 18: $1805-1811$

32. Schaeren-Wiemers N, Gerfin-Moser A (1993) A single protocol to detect transcripts of various types and expression levels in neural tissue and cultured cells: in situ hybridization using digoxigeninlabelled cRNA probes. Histochemistry 100(6):431-40

33. Schnabel R, Kilpatrick IC, Collingridge GL (1999) An investigation into signal transduction mechanisms involved in DHPGinduced LTD in the CA1 region of the hippocampus. Neuropharmacology 38:1585-1596

34. Shipman SL, Nicoll RA (2012) A subtype-specific function for the extracellular domain of neuroligin 1 in hippocampal LTP. Neuron 76:309-316

35. Silva AJ, Stevens CF, Tonegawa S, Wang Y (1992) Deficient hippocampal long-term potentiation in alpha-calcium-calmodulin kinase II mutant mice. Science 257:201-206

36. Vennekens R, Menigoz A, Nilius B (2012) TRPs in the brain. Rev Physiol Biochem Pharmacol 163:27-64

37. Vennekens R, Olausson J, Meissner M, Bloch W, Mathar I, Philipp SE, Schmitz F, Weissgerber P, Nilius B, Flockerzi V, Freichel M (2007) Increased IgE-dependent mast cell activation and anaphylactic responses in mice lacking the calcium-activated nonselective cation channel TRPM4. Nat Immunol 8:312-320

38. West AE, Chen WG, Dalva MB, Dolmetsch RE, Kornhauser JM, Shaywitz AJ, Takasu MA, Tao X, Greenberg ME (2001) Calcium regulation of neuronal gene expression. Proc Natl Acad Sci U S A 98:11024-11031

39. Yasuda R, Sabatini BL, Svoboda K (2003) Plasticity of calcium channels in dendritic spines. Nat Neurosci 6:948-955

40. Yoo JC, Yarishkin OV, Hwang EM, Kim E, Kim DG, Park N, Hong SG, Park JY (2010) Cloning and characterization of rat transient receptor potential-melastatin 4 (TRPM4). Biochem Biophys Res Commun 391:806-811 